Universidad de Lima

Facultad de Psicología

Carrera de Psicología

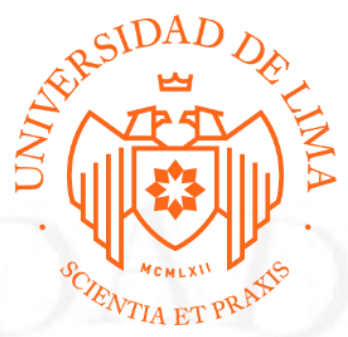

\title{
INTERVENCIÓN COGNITIVO CONDUCTUAL PARA LA REDUCCIÓN DE LA ANSIEDAD EN ADOLESCENTES DE UN CENTRO PSICOLÓGICO PRIVADO
}

Trabajo de suficiencia profesional para optar el título profesional de licenciada en

Psicología

Ana Giselle Zapata Arias

20132376

Asesora

Zoila Magaly Flores Giles

Lima - Perú

Marzo del 2020 


\section{COGNITIVE BEHAVIORAL INTERVENTION FOR ANXIETY IN ADOLESCENTS OF A PRIVATE THERAPEUTIC INSTITUTION}




\section{TABLA DE CONTENIDO}

CAPÍTULO I: CONTEXTUALIZACIÓN DE LA PROBLEMÁTICA.............. 1

1.1 Descripción del problema...................................................

1.2 Análisis institucional.......................................................

CAPÍTULO II: MARCO TEÓRICO Y ANTECEDENTES..........................5

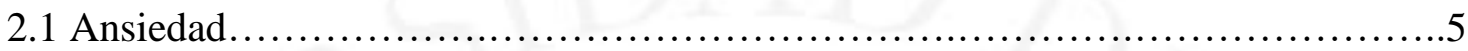

2.1.1 Factores predisponentes..............................................

2.1.2 Consecuencias............................................................ 8

2.2 Terapia cognitivo conductual para la ansiedad en adolescentes...................8

CAPÍTULO III: OBJETIVOS GENERAL Y ESPECÍFICOS...................10

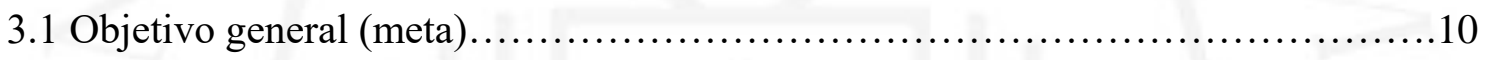

3.2 Competencia general................................................... 10

3.3 Resultados de aprendizaje.............................................. 10

CAPÍTULO IV: METODOLOGÍA DE LA EVALUACIÓN Y DE LA

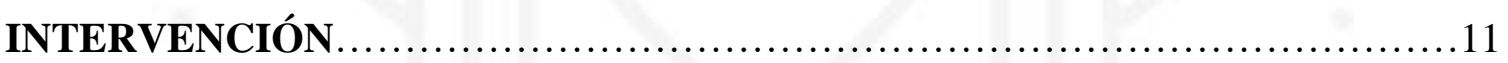

4.1 Evaluación de línea base...................................................11

4.1.1 Participantes........................................................... 11

4.1.2 Técnicas y/o instrumentos de evaluación/diagnóstico.........................11

4.1.3 Procedimientos de evaluación de línea base.......................................13

4.2 Implementación...................................................... 14

4.2.1 Participantes......................................................... 14

4.2.2 Instrumentos o herramientas de implementación/intervención..................14

4.2.3 Procedimiento de implementación.......................................16

4.3 Evaluación de proceso................................................... 19 
4.3.1 Participantes. 19

4.3.2 Técnicas y/o instrumentos de evaluación/diagnóstico..... 19

4.3.3 Procedimiento de evaluación de proceso..................................... 19

CAPÍTULO V: RESULTADOS..................................................21

5.1 Resultados descriptivos cuantitativos........................................ 21

5.2 Resultados interpretativos.................................................. 22

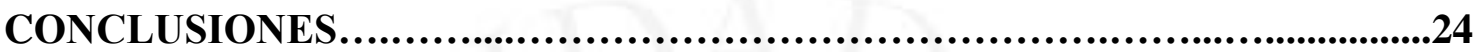

RECOMENDACIONES..........................................................25

REFERENCIAS.................................................................26

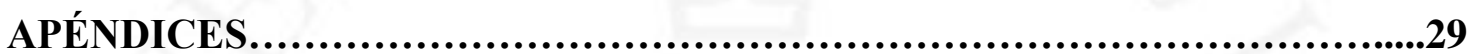




\section{ÍNDICE DE TABLAS}

Tabla 5.1: Nivel de ansiedad en la evaluación de línea base y de proceso ..............21

Tabla 5.2: $t$ de student para la evaluación de línea base y de proceso ..................22

Tabla 5.3: Comparación entre los SUD inicial y final aplicados en la tercera sesión ......22 


\section{ÍNDICE DE FIGURAS}

Figura 4.1: Estructura de la intervención....................................17 


\section{ÍNDICE DE APÉNDICES}

APÉNDICE 1: Formato de entrevista psicológica del centro terapéutico

APÉNDICE 2: Ficha técnica del Inventario de Ansiedad de Beck (BAI)

APÉNDICE 3: Versión española del Inventario de Ansiedad de Beck (BAI)

APÉNDICE 4: Permiso institucional para la utilización de la información necesaria 38

APÉNDICE 5: Consentimiento informado dirigido a los padres de los participantes 39

APÉNDICE 6: Estructura completa de las sesiones $\quad 40$

APÉNDICE 7: Ficha "Ansiedad: amiga o enemiga" 48

APÉNDICE 8: Autorregistros $\quad 49$

$\begin{array}{lr}\text { APÉNDICE 9: Registro de relajación } & 50\end{array}$

APÉNDICE 10: Matriz organizativa adaptada 


\section{RESUMEN}

La adolescencia es una época de cambios a nivel físico, neurológico, cognitivo y conductual, considerada como una época de crisis, con mayor vulnerabilidad a desarrollar problemas de salud mental como la ansiedad. Esto supone consecuencias en los diversos planos de su vida, como bajo rendimiento académico, dificultades en habilidades sociales, baja autoestima, problemas familiares y mayor propensión a desarrollar trastornos depresivos.

En el último año, los niveles altos de ansiedad han sido el problema más encontrado en el centro terapéutico a trabajar. Por consiguiente, se plantea un programa de intervención cognitivo conductual, en el cual participaron cinco adolescentes de 13 a 15 años de edad. Su objetivo fue reducir los niveles de ansiedad, a través de tres módulos, con un total de 14 sesiones. Se abordaron los síntomas fisiológicos, distorsiones cognitivas y conductas disfuncionales, enmarcándose en el modelo cognitivo de la ansiedad de Beck.

Se ejecutaron tres sesiones, aplicando el Inventario de Ansiedad de Beck en la evaluación de línea base y de proceso. Los niveles de ansiedad se mantuvieron en un nivel moderado después de la ejecución de las sesiones; además, se encontraron descensos en los índices de malestar subjetivo (SUDS) al realizar las técnicas de respiración y relajación.

Palabras claves: ansiedad, adolescentes, terapia cognitivo conductual, Beck. 


\begin{abstract}
Adolescence is a time of changes at physical, neurological, cognitive and behavioral level, considered as a time of crisis, with vulnerability to develop mental health problems such as anxiety. This implies consequences in various levels of their lives, such as poor academic performance, difficulties in social skills, low self-esteem, family problems and a greater propensity to develop depressive disorders.

In the last year, high levels of anxiety have been the most common problem in the therapeutic center in which we worked. Therefore, a cognitive behavioral intervention program is proposed, in which five adolescents aged 13 to 15 years participated. Its objective was to reduce anxiety levels, through three modules, with a total of 14 sessions. Physiological symptoms, cognitive distortions and dysfunctional behaviors were addressed, being framed in Beck's cognitive model of anxiety.

Three sessions were run, applying Beck's Anxiety Inventory in the baseline and process evaluation. Anxiety levels remained at a moderate level after the execution of the sessions; In addition, there were decreases in the rates of subjective discomfort (SUDS) when performing breathing and relaxation techniques.
\end{abstract}

Keywords: anxiety, adolescents, cognitive behavioral intervention, Beck. 


\section{CAPÍTULO I: CONTEXTUALIZACIÓN DE LA PROBLEMÁTICA}

\subsection{Descripción del problema}

La adolescencia es una etapa de crisis, en la que se viven muchos cambios a nivel físico y mental. En dicha etapa, los adolescentes suelen alterar su forma de percibir el mundo. Pueden surgir pensamientos que a veces no favorecen un procesamiento funcional de la información de su contexto. Cuando esto sucede, dicha población podría ser más propensa a padecer problemas de salud mental. La mitad de dichos problemas suelen comenzar a los 14 años; sin embargo, en muchas ocasiones, no son detectados ni tratados, ya sea por estigmatización cultural, falta de servicios de salud, o por la falta de un diagnóstico oportuno. Esto deriva en dificultades en la edad adulta, además de ser un obstáculo en el desenvolvimiento normal, limitando oportunidades e impidiéndoles llevar una vida plena (Organización Mundial de la Salud [OMS], 2018); Simon, 2016).

A nivel mundial, del total de casos atendidos con algún trastorno psicológico, el $70 \%$ fueron niños y adolescentes. Los problemas de ansiedad y depresión fueron los más encontrados en dicha población (Ticona, 2014; Organización Panamericana de la Salud [OPS], 2018). Igualmente, la OMS (2019) recalca que el 11,4\% del total de adolescentes presentan un problema de salud mental, encontrándose que la ansiedad es la sexta enfermedad más común en dicho grupo de edad. A nivel nacional, un $13 \%$ de niños y adolescentes, entre las edades de 9 a 17 años, experimenta algún tipo de trastorno de ansiedad; siendo el género femenino el más afectado (Ministerio de Salud del Perú [MINSA], 2018; Instituto Nacional de Salud Mental Honorio Delgado Hideyo Noguchi [INSM], 2012).

De la misma manera, el INSM (2012) declara que el 43\% del número total de intervenciones realizadas en el hospital fueron dirigidas a niños y adolescentes. En el caso del Hospital Víctor Larco Herrera (2019), la mayoría de casos nuevos atendidos llega por ansiedad.

Cabe mencionar que existen algunos factores que predisponen que los adolescentes experimenten. En primer lugar, se encuentran las propias características de esta etapa, la cual involucra cambios físicos, emocionales y sociales, acompañados de 
una búsqueda de mayor independencia y de una necesidad de experimentar nuevas sensaciones. Por esta razón, la etapa es considerada un proceso de crisis, en la que se establecen nuevas formas de entender e interactuar con la realidad, lo que muchas veces supone alejarse de sus padres (OMS, 2018; López, 2014). Otro factor importante es el constante cambio que se da en el entorno. El ritmo de vida más acelerado se caracteriza por ejercer más presión por obtener logros o reconocimientos desde muy pequeños. La dinámica familiar ha ido modificándose, lo que se manifiesta en el aumento de los divorcios o la ausencia de ambos padres por cumplir con sus responsabilidades laborales, lo cual repercute en las emociones del adolescente. Dicha influencia puede ser negativa si es que no se encuentra bien dirigida o acompañada (Aparicio y Zermeño, 2010; Instituto Nacional de Estadística e Informática [INEI], 2016). Dichas consecuencias son más probables cuando el adolescente no presenta límites adecuadamente establecidos, además de no contar con un apoyo constante o con una guía por parte de su familia (Moreno, 2013; Capo, 2011). El riesgo aumenta aún más cuando son expuestos a factores de riesgo como la pobreza, el abuso o la violencia (OMS, 2018).

Como consecuencia, los problemas de ansiedad y depresión en adolescentes se encuentran asociados al $16 \%$ de muertes y lesiones en dicha población; además, diversas investigaciones evidencian una relación entre la baja autoestima y los niveles altos de ansiedad, lo que provoca que el desarrollo de su autoeficacia, individuación y confianza en sus propios recursos se vea afectado (OMS, 2019; Núñez y Crismán, 2016) El ámbito escolar también percibe repercusiones asociadas a la ansiedad, afectando la motivación del alumno, provocando conductas disruptivas y repercutiendo negativamente en el rendimiento académico. Asimismo, facilita el aislamiento y las dificultades en las relaciones sociales, influyendo en los futuros logros ocupacionales en la edad adulta. Cabe resaltar que puede coexistir con otros trastornos del estado de ánimo o conductuales; así como en los estilos de afrontamiento y en la competencia adecuada para resolver problemas personales y sociales (Núñez y Crismán, 2016; OMS, 2019; Santos y Vallín, 2018).

Finalmente, dada la alta prevalencia de niveles altos de ansiedad en la población escogida, tanto a nivel nacional como en el centro terapéutico a trabajar, se propone el presente programa individual. Este tiene como fin favorecer el bienestar psicológico en los pacientes escogidos, disminuyendo sus niveles de ansiedad a través de terapia de tipo cognitivo conductual. En paralelo, se busca que logren responder adecuadamente a las 
demandas del ambiente y tengan un buen desenvolvimiento en las diversas áreas de su vida, favoreciendo una buena salud física y mental en la edad adulta. la intervención podrá favorecer el diagnóstico y tratamiento oportuno de la ansiedad en los adolescentes, con el fin de que no repercutan negativamente en su vida futura.

Cabe resaltar que, para el desarrollo del presente trabajo, debido a los diferentes significados que se le asigna al término ansiedad, en adelante se utilizará el término para designar a los niveles altos de la misma.

\subsection{Análisis institucional}

La institución en la cual se llevará a cabo la intervención se encuentra en el rubro de Terapias infanto-juveniles, posee 7 años de servicio y, actualmente, cuenta con diez trabajadores, de los cuales seis pertenecen al área de psicología, en la cual se realizará la intervención. A su vez, el enfoque predominante del centro es de tipo cognitivo conductual, encontrándose que tres de los profesionales poseen formación en psicoterapia de este tipo y solo una se formó en terapia gestáltica.

El centro se encarga de brindar evaluaciones y terapias psicológicas, de lenguaje y ocupacionales. Su accionar se orienta a brindar servicios terapéuticos especializados con el fin de prevenir, detectar y atender oportunamente diversas alteraciones en los niños, adolescentes y familias, interviniendo de forma pertinente y multidisciplinaria. Además, busca ser un centro terapéutico con reconocimiento por parte de la sociedad, líder en la promoción, prevención y tratamiento de diversas alteraciones; demostrando su compromiso a través de los valores de confidencialidad, profesionalismo, solidaridad, empatía y vocación de servicio. El trato cordial y amable que se le brinda a cada familia es un ejemplo de dicho compromiso.

Sus objetivos principales se centran en brindar servicios de calidad, realizar diagnósticos oportunos y acertados, y ejecutar intervenciones pertinentes, alineadas a las necesidades individuales de cada paciente. Otro de sus objetivos consiste en contribuir en el desarrollo y fortalecimiento de las habilidades socioemocionales de los niños y adolescentes, las cuales son requeridas para permitirles desenvolverse adecuadamente y afrontar las vicisitudes de su entorno. No obstante, el centro no realiza un análisis de su base de datos, por lo que suele desconocer las problemáticas más recurrentes entre sus 
clientes. Dicho conocimiento favorecería el diseño de planes de intervención alineados a las necesidades de sus pacientes.

Por esta razón, en el presente trabajo se realiza un análisis de los casos recibidos en el último año, utilizando los resultados derivados de la evaluación integral (procedimiento inicial que se lleva a cabo con todos los pacientes). Dicha evaluación consiste en explorar el desempeño a nivel cognitivo, socioemocional, de desarrollo y dinámica familiar. Se empieza con una entrevista a los padres; luego, al paciente y, posteriormente, se aplican diversas pruebas psicométricas y proyectivas, que van definiéndose dependiendo del caso a evaluar. Al término de la evaluación, se entrega el informe psicológico y se realiza una devolución de resultados a los padres, invitándolos a continuar con la terapia psicológica para aquellos pacientes que lo necesitan. A raíz del análisis de dichos informes psicológicos se encuentra que, en el área de psicología, se atendió a un número total de 246 pacientes, encontrándose que el 17\% de ellos tenían de 2 a 4 años, $26 \%$ tenían entre 5 a 8 años, 22\% entre 9 a 12 años y $35 \%$ con edades de 13 a 16 años. De este último grupo, el $45 \%$ llegaron por derivación del colegio debido a problemas de conducta, bajo rendimiento académico o dificultades socioemocionales, percibidas en dichas instituciones. A su vez, se encuentra que los síntomas de ansiedad son el problema más frecuente, hallándose en el $72 \%$ de pacientes.

Los resultados reflejan la necesidad de intervenir en la población más recurrente en el centro; es decir, los adolescentes de 13 a 16 años, los cuales presentan en mayor medida niveles altos de ansiedad. Dicho problema afecta su funcionamiento en diversas áreas y no les permite gozar de un estado de bienestar. Al no ser tratados, podrían derivar en conductas de riesgo, problemas de autoestima, bajo rendimiento académico, conductas disruptivas y dificultades para relacionarse con los demás, así como conflictos familiares más recurrentes. A largo plazo, podrían provocar mayores dificultades en la edad adulta, favoreciendo el desarrollo de trastornos como la depresión.

De esta forma, se propone un modelo de intervención para casos de adolescentes con niveles altos de ansiedad, el cual le permitirá al paciente reducirla a través de técnicas cognitivo conductuales, al ser el enfoque más utilizado en el centro. Los participantes del programa podrán beneficiarse de los efectos de una intervención alineada a sus necesidades. 


\section{CAPÍTULO II: MARCO TEÓRICO Y ANTECEDENTES}

\subsection{Ansiedad en adolescentes}

La adolescencia se considera un periodo de crisis, ya que es una etapa transicional caracterizada por cambios biológicos, neurológicos, psicológicos e interpersonales que suceden rápidamente. Su cerebro es aún inmaduro; la corteza prefrontal, encargada del manejo de las funciones ejecutivas, se encuentra desarrollándose. Dichas funciones hacen referencia al control e inhibición de los impulsos, planificación y automonitoreo de conductas, toma de decisiones, anticipación de consecuencias a corto, mediano y largo plazo, y flexibilidad cognitiva. Asimismo, sus esquemas centrales, los que le permiten interpretar las situaciones de cierta forma, aún se encuentran en formación. Al encontrarse aún en desarrollo, se trata de una etapa sensible, en la que pueden producirse cambios psicológicos importantes, ya sean positivos o negativos, influenciados por su contexto y por las vivencias ocurridas en este periodo (Diz, 2013; Gomar, Mandil y Bunge, 2011). Frith (como se citó en Diz, 2013) declara que el cerebro adolescente es adaptable y debe ser moldeado y modelado; además, menciona que las vivencias en esta etapa son cruciales, ya que podrían favorecer la aparición de trastornos mentales con mayor facilidad. Los contextos familiares disfuncionales, con estilos de crianza autoritarios y sobreexigencia en el hogar; así como la falta de apoyo constante o la presencia de un familiar con problemas de salud puede influenciar en la aparición de dichos trastornos (Guisa et al., 2013; Capo, 2011; OMS, 2018; López, 2014; Gomar et al., 2012).

Entre una de las dificultades más comunes entre los adolescentes se encuentra la ansiedad, la cual se caracteriza por ser un estado subjetivo anticipatorio de miedo o tensión; asimismo, se le considera un complejo sistema de respuesta que se activa al percibir una amenaza o al anticipar situaciones que se consideran muy aversivas, imprevisibles e inmanejables, que potencialmente podrían amenazar los intereses vitales de una persona (Beck y Clark, 2012; Hartmann, 2019). Las situaciones consideradas como más ansiógenas para este grupo de edad son las pruebas o exámenes; así como sentirse socialmente excluido o burlado (Gomar et al., 2012).

En ocasiones, el adolescente suele imaginarse metas inalcanzables, por lo que termina fallando para conseguirlo. Muchos tienen que enfrentar constantes competencias, 
expectativas irrealistas y muchas distracciones. Por esta razón, no es extraño que los problemas de salud mental suelan manifestarse a esta edad (Manju y Rajesh, 2015). Asimismo, el diagnóstico y tratamiento oportuno de los síntomas de ansiedad permite evitar que estos persistan en la edad adulta; sin embargo, en muchas ocasiones, se les subestima, considerando que son solo producto de los estados emocionales cambiantes propios de la edad, que son transitorios o irreales (Cárdenas, Feria, Palacios y De la Peña, 2010).

En el presente trabajo se considera la ansiedad en niveles altos, la cual afecta el funcionamiento en algunas áreas de la vida de la persona, pero no llega a ser un trastorno ya que no cumple con los criterios suficientes. A continuación, se presentan algunas de sus manifestaciones:

- Síntomas fisiológicos, tales como aumento de las pulsaciones cardíacas, respiración entrecortada o acelerada, dolor o presión en el pecho, náuseas, temblores, adormecimiento, tensión, mareos o sudoración (Beck y Clark, 2012; Díaz, 2019).

- Síntomas cognitivos, como miedo a perder el control, a ser juzgado, a no poder controlarlo, falta de objetividad, etc. A su vez, se activan los esquemas disfuncionales acerca de la amenaza y se presentan los errores en el procesamiento cognitivo (Beck y Clark, 2012; Beck et. al., 2002; CanoVindel, Dongil-Collado, Salguero y Wood, 2013).

- Síntomas conductuales; como la inquietud, la dificultad para hablar o los comportamientos de evitación. Estos últimos pueden ser manifiestos; es decir, buscan alejarse de las situaciones que le causan ansiedad o inventan excusas para no exponerse a dichas situaciones. También se da el caso que la persona sí se involucra en las situaciones que le causan ansiedad, pero en vez de encontrarse enfocados en eso, suelen preocuparse constantemente por lo que podría suceder; además, pueden perder la capacidad de disfrutar la vida y de actuar de forma funcional en las diversas áreas de su vida (Beck y Clark, 2012; Barlow, 2018; Reyes, 2019).

- Síntomas afectivos, como sentirse tenso, nervioso, temeroso, inquieto, impaciente o frustrado (Beck y Clark, 2012). 


\subsubsection{Factores predisponentes}

De acuerdo a Beck y Clark (2012), existen ciertos factores que pueden provocar que la persona sea más vulnerable a la ansiedad. El primero de ellos aborda los determinantes biológicos, como el temperamento, los factores genéticos y los neurofisiológicos. El segundo los rasgos de personalidad, que hacen referencia a rasgos personales que pueden hacer que la persona se encuentre más propensa a actuar de forma más emocional y a una mayor cantidad de estímulos. Luego, la sensación de disminución del control personal, la cual puede producirse por una niñez sobreprotegida. El último factor aborda los acontecimientos vitales negativos, que en algún momento causaron una amenaza o daño a su propia integridad o a sus intereses personales, pueden aumentar el riesgo de padecer ansiedad.

\subsubsection{Consecuencias}

En los adolescentes, niveles altos de ansiedad pueden afectar negativamente su desenvolvimiento personal, generando problemas en su camino hacia la independencia e individuación, así como un impedimento en el desarrollo de su autoeficacia, sus habilidades de afrontamiento sociales, y la capacidad para la resolución de problemas personales y sociales apropiados para la edad (Simon, 2016). Adicionalmente, una baja autoestima se relaciona con una mayor propensión a la ansiedad (Núñez y Crismán-Pérez, 2016; Calla e Infantes, 2020).

Asimismo, la ansiedad se asocia a errores en el procesamiento de la información, provocando la valoración de situaciones o eventos como amenazantes e irrealistas. Dicha percepción no favorece una adecuada capacidad de afrontamiento, ya que se percibe la situación como muy difícil de sobrellevar, lo que favorece el temor al fracaso y la sensación de incapacidad en cuanto al control de situaciones y reacciones ante estas (Simon, 2016). El adolescente, al presentar dichos pensamientos recae en conductas de evitación, lo que no le permite desarrollar las actividades de su vida diaria con normalidad y cumplir las exigencias de su medio. Dicha incapacidad conlleva a un deterioro en las diversas áreas de funcionamiento de la persona, ya sea en el ámbito social, académico, familiar y personal (Díaz, 2019).

Por último, su funcionamiento psicosocial, sus habilidades sociales y su rendimiento académico pueden verse afectados. Si no se recibe un tratamiento oportuno, 
existe mayor riesgo de abuso de sustancias y de desarrollar trastornos como la depresión en el futuro (Rasing, Creemers, Janssens y Scholte, 2013; Sánchez, Ontiveros y Granados, 2019; Cevallos y Proaño, 2016; Gonzáles, Guevara, Jiménez y Alcázar, 2018).

\subsection{Terapia cognitivo conductual para la ansiedad en adolescentes}

La terapia cognitivo conductual se trata de un tipo de intervención que busca trabajar con las respuestas disfuncionales físicas, emocionales, cognitivas y conductuales, de carácter aprendido; es decir, que se han practicado a lo largo del tiempo y se han convertido en hábitos (Ruiz, Díaz y Villalobos, 2012; Martin-Romo, 2012). Dicha terapia cuando se dirige a la ansiedad se enmarca en un modelo cognitivo. Este indica que las experiencias tempranas vividas forman un esquema cognitivo, el cual da lugar a una forma de pensamiento. Dicho pensamiento actúa de moderador entre el estímulo y el sentimiento. La ansiedad surge debido a que la persona presenta una valoración o pensamiento de tipo ansioso, exagera la amenaza y subestima su propia capacidad de afrontamiento o los factores de rescate. A su vez, se mantiene por las conductas de evitación, que reducen los niveles de ansiedad y la refuerzan. Una persona con niveles altos de ansiedad suele presentar atención selectiva a las amenazas y percepción de ausencia de medidas de seguridad que le permitan afrontar la problemática (Beck y Clark, 2012; Beck, Emery y Greenberg, 2005).

La terapia cognitivo conductual ha demostrado eficacia en el tratamiento de la ansiedad en adolescentes. Diversas investigaciones confirman sus efectos positivos e incluso la vinculan con cambios a largo plazo, que favorecen el bienestar psicológico de los pacientes (Gallagher, et. al, 2020; Miranda, 2018; Fernández, 2018; Huertas, 2018). Una investigación realizada por Moreno (2016) evidencia que, luego de la terapia, los participantes presentaron cambios morfológicos y funcionales en regiones del cerebro relacionadas con la fisiopatología de la ansiedad.

El psicoterapeuta debe considerar las diferencias individuales propias de los adolescentes que podrían impactar en la terapia. Una de ellas es el egocentrismo, que les dificulta comprender los puntos de vista de otras personas. Para esto, el terapeuta debe buscar transmitirle sus esfuerzos por comprender su punto de vista y no buscar contradecirlo, esto con el fin de que el paciente no esté a la defensiva. Lo segundo importante sería fomentar la colaboración, buscando una relación terapéutica más 
igualitaria, en la que el adolescente pueda tomar decisiones sobre lo que se realiza y los objetivos que se quieren alcanzar. Asimismo, es necesario mantener la objetividad, ya que el paciente buscará que el terapeuta comparta su punto de vista, por lo que este debe actuar de moderador y ayudar a que la propia persona compruebe sus creencias, ayudando a que sus conclusiones no se encuentren sesgadas. A su vez, es importante reconocer el pensamiento dicotómico de este grupo de edad, para lo cual se busca favorecer la identificación de alternativas intermedias. Por último, es beneficioso que se incluya a personas de su contexto en la terapia, con el objetivo de que les brinden facilidades para cumplir con las tareas que se le asignen, ya que muchas veces los pacientes no pueden tomar decisiones por su propia cuenta debido a la edad; además, incluir familiares les brinda otra perspectiva (Stallard, 2007; Gomar et al., 2012).

Asimismo, se reconoce que la mayor parte del sufrimiento humano surge de creencias irracionales, supuestos o significados personales adquiridos en la experiencia. Dichos pensamientos pueden ser modificados; es así que el psicólogo presta especial interés en transmitir a la persona su capacidad de modificar dichos pensamientos y a ser más conscientes de estos, aunque a veces crean que no pueden ser cambiados. Además, debe mostrar en todo momento una actitud y comprensión activa, tanto en la evaluación de las distorsiones cognitivas como en las distintas técnicas aplicadas, buscando de esta forma generar una modificación en su sistema cognitivo y un posterior cambio conductual (Martin-Romo, 2012).

Para esto, el psicólogo debe ser capaz de realizar una evaluación del caso apropiada, considerando los síntomas presentes y prestando atención a las distorsiones cognitivas. Posteriormente, deben establecerse los objetivos terapéuticos entre el paciente y el psicólogo. En base a dichos objetivos, se plantean las técnicas a utilizar en la sesión. Cabe resaltar que la terapia involucra intervenciones de reestructuración cognitiva y resolución de problemas con estrategias conductuales. A su vez, se debe contemplar cambiar la perspectiva de peligro y vulnerabilidad personal exagerados a una visión más funcional, con una sensación de amenaza, pero mínima y aceptable, con reconocimiento de sus capacidades de afrontamiento y de las señales de seguridad. A su vez, es necesario normalizar la ansiedad, con el fin de ayudar al paciente a no sentirse tan aislado y absorto en sus síntomas ansiosos (Cano-Vindel et al., 2013; Beck y Clark, 2012; Gomar et al., 2012). 


\section{CAPÍTULO III: OBJETIVOS GENERAL Y ESPECÍFICOS}

\subsection{Objetivo general (meta)}

Reducir los niveles de ansiedad en adolescentes entre 13 y 15 años de edad que asisten a un centro terapéutico privado.

\subsection{Competencia general}

- Aplica técnicas de respiración y relajación para disminuir los síntomas de activación fisiológica de ansiedad.

- Emplea técnicas de reestructuración cognitiva para modificar sus pensamientos ansiógenos.

- Utiliza técnicas de exposición durante situaciones que le producen ansiedad.

\subsection{Resultados de aprendizaje}

- Conoce las características de la ansiedad, tales como las respuestas fisiológicas, conductuales y cognitivas.

- Conoce las técnicas de respiración y relajación.

- Utiliza las técnicas de respiración y relajación.

- Reconoce el efecto de sus pensamientos en sus emociones y conductas.

- Distingue los diferentes tipos de distorsiones cognitivas.

- Identifica sus distorsiones cognitivas

- Busca pensamientos alternativos más funcionales

- Identifica el problema y realiza una lista de posibles soluciones

- Analiza y escoge la mejor alternativa entre las posibles soluciones, evaluando sus pros y contras

- Reconoce las señales de seguridad del ambiente para afrontar las situaciones.

- Reconoce la influencia de la evitación en el mantenimiento de la ansiedad.

- Se expone a situaciones que le provoquen ansiedad. 


\section{CAPÍTULO IV: METODOLOGÍA DE LA EVALUACIÓN Y DE LA INTERVENCIÓN}

\subsection{Evaluación de línea base}

\subsubsection{Participantes}

Los participantes de la evaluación de línea base fueron cinco adolescentes, tres mujeres y dos varones. Sus edades oscilaron entre los 13 y 15 años. Se eligieron a los pacientes con síntomas de ansiedad en la evaluación integral. Dichos pacientes ya habían recibido la devolución de informe y se encontraban a la espera del inicio de su terapia psicológica. Por otro lado, ninguno presentaba trastornos del neurodesarrollo.

\subsubsection{Técnicas y/o instrumentos de evaluación/diagnóstico}

\section{Inventario de Ansiedad de Beck (BAI)}

Con el fin de medir los síntomas ansiosos de la población a tratar, se utilizó el Inventario de Ansiedad de Beck (BAI), el cual se elabora para medir la sintomatología de la ansiedad, como una medida fiable para distinguirla de la depresión; además, se encarga de evaluar síntomas cognitivos, emocionales, motores y fisiológicos (Beck y Steer, 2011). La versión original fue desarrollada por Beck, Epstein, Brown y Steer (1988) y fue adaptada al español luego de diversos estudios en muestras diferentes (ver Apéndice 2) (Magán, Sanz y García-Vera, 2008; Sanz, García-Vera y Fortún, 2012; Sanz y Navarro, 2003).

Dicha escala se basa en lo que la persona sintió en la última semana; asimismo, es de tipo autoinforme y mide la gravedad de la ansiedad en adolescentes y adultos desde los 13 años. A su vez, está conformada por 21 ítems y utiliza una escala Likert de 4 puntos, que va desde 0 (Nada, en absoluto) y 3 (Gravemente, casi no podía soportarlo). En cuanto a la puntuación total, se obtiene un puntaje mínimo de 0 puntos y un máximo de 63. En el caso que el paciente obtenga puntuaciones entre 0 y 7 , indicaría un nivel de ansiedad mínimo; si obtiene de 8 a 15 puntos, sería leve; de 16 a 25 sería moderada; y de 26 a 63 sería grave (Beck y Steer, 2011). Cabe mencionar que esta es una prueba que, 
dada su corta extensión, se puede aplicar en el curso de la terapia para observar los progresos (Sanz, 2014).

En cuanto a sus propiedades psicométricas, la adaptación española del Inventario de Ansiedad de Beck (BAI) (Beck y Steer, 2011) se enfoca en un análisis de las evidencias de validez relacionadas a la estructura interna, convergente y discriminante y de criterio; así como de la consistencia interna de las puntuaciones de tres tipos de poblaciones diferentes. La primera consistía en dos grupos de pacientes con trastornos psicológicos, con un total de 392 personas. La segunda formada por dos muestras de adultos de la población general que totalizaron 348 adultos. La última conformada por dos muestras de estudiantes universitarios, que llegaban a los 727. Dichos análisis evidencian los buenos índices que obtiene la adaptación española del BAI para medir la presencia y gravedad de los síntomas ansiosos (Magán et al., 2008; Sanz et al., 2012; Sanz y Navarro, 2003).

En relación a su consistencia interna, esta se midió utilizando el coeficiente de confiabilidad $\alpha$ de Cronbach, en las diferentes poblaciones de pacientes con trastornos psicológicos, adultos de la población general y estudiantes universitarios, obteniendo como coeficientes $.90, .91$ y .88, respectivamente, considerados excelentes, ya que son mayores a 85 (Prieto y Muñiz, 2000; Sanz, 2014).

Adicionalmente, para obtener las evidencias de validez vinculadas a la estructura interna, se realizó un análisis factorial exploratorio. En dicho análisis se obtuvo que la prueba mide una dimensión general de ansiedad compuesta de dos factores relacionados, los cuales abordan los síntomas somáticos y afectivo-cognitivos (Magán et al., 2008; Sanz et al., 2012; Sanz y Navarro, 2003).

Con respecto a las evidencias de validez relacionadas al constructo, estas se midieron para obtener datos sobre la capacidad del test para identificar un trastorno de ansiedad, diferenciándolo de otros tipos de dificultades. Para esto, se compararon los resultados de la aplicación del BAI con los derivados de la aplicación del Inventario de Depresión de Beck II (Beck, Steer y Brown, 1996). Asimismo, se empleó la curva de las características operativas del receptor o curva ROC, la cual evidenció que demostraba un buen rendimiento en el diagnóstico de síntomas de ansiedad (Sanz, 2014).

Además, se utilizó la $d$ de Cohen con la intención de contrastar los resultados de los diferentes grupos (pacientes con trastornos psicológicos, adultos de la población 
general y estudiantes universitarios). Dichos análisis obtuvieron puntajes de .81 y 1.01 , lo cual permite concluir que la puntuación media del BAI, derivado de los resultados de los pacientes con algún trastorno psicológico, es significativamente mayor si se compara con los puntajes de los adultos de la población general y los estudiantes universitarios, siendo casi el doble de diferencia (Beck y Steer, 2011; Magán et al., 2008; Sanz et al., 2012; Sanz y Navarro, 2003).

\subsubsection{Procedimientos de evaluación de línea base}

En primer lugar, se solicitaron los permisos a la directora del centro terapéutico para poder utilizar la información derivada de la evaluación y hacer uso de las instalaciones para poder llevarla a cabo (ver Apéndice 4). Luego, se solicitaron los permisos a los padres de los participantes, se les explicó el proceso de evaluación y se les solicitó que firmen el consentimiento (ver Apéndice 5).

Dicha evaluación comenzó con la entrevista a los padres, previa a la evaluación integral (procedimiento inicial que evalúa el área cognitiva, socioemocional, de desarrollo y dinámica familiar). Luego, se entrevistaron a los pacientes, a los cuales se les consultó sobre las dificultades que atravesaban y se identificaron los síntomas predominantes; además, se les conversó sobre la evaluación y se terminó de recabar la información que faltaba. Dicho procedimiento se tomó en consideración para la intervención.

Posteriormente, se les convocó, vía telefónica, a una nueva cita para comenzar la intervención. Previo a la primera sesión, de forma individual y en uno de los consultorios del centro terapéutico, se realizó la aplicación del Inventario de Ansiedad de Beck. Primero, se les explicó que el test contiene una serie de síntomas propios de la ansiedad, se les indicó que los lea y marque la alternativa que refleje mejor el grado en que ese síntoma le afectó durante la última semana. Se les entregó un lápiz para que puedan responder. Asimismo, se recalcó que conteste con sinceridad ya que no hay respuestas malas ni buenas. Luego de la aplicación, se pudo realizar la primera sesión de intervención.

En cuanto a los resultados, estos se calcularon sumando los puntajes de la prueba, la cual tiene calificaciones que van del 0 (Nada en absoluto) al 3 (Severamente, casi no 
podía soportarlo). Dichas puntuaciones se sumaron y se obtuvo el puntaje total, el cual se coloca en una categoría.

\subsection{Implementación}

\subsubsection{Participantes}

Los participantes de la intervención fueron los mismos que se presentaron en la evaluación de línea base. Todos los participantes asistieron a las sesiones individuales.

\subsubsection{Instrumentos o herramientas de implementación/intervención}

Las técnicas terapéuticas utilizadas en el presente programa de intervención fueron las siguientes:

\section{Psicoeducación (ver Apéndice 6)}

Dicha técnica sienta las bases para una posterior reestructuración cognitiva e influye en los componentes conductuales del tratamiento; además, busca explicar cómo funciona la ansiedad, su modelo cognitivo y las formas de mantenimiento de la misma. Esto permite que el paciente reconozca cómo se manifiesta en él, le ayuda a comprender su problema y favorece su normalización, con el fin de reducir los síntomas afectivos (Bunge, Gomar y Mandil, 2009). Dicha normalización involucra comprender que la ansiedad es algo común, lo que favorece que el paciente no se sienta solo con su dificultad y no se sienta diferente a los demás. Comprender el curso de la ansiedad le permite reducir los síntomas de impotencia y le sugiere la posibilidad de mejorar (Cano-Vindel et al., 2013; Beck y Clark, 2012; Gomar et al., 2012).

\section{Relajación o manejo somático}

Favorece el manejo de los síntomas fisiológicos, entre las más útiles se encuentran la relajación muscular profunda, la imaginación guiada y la respiración profunda. Practicar estas estrategias le permite percatarse de que los síntomas ansiosos no son inmanejables. Adicionalmente, es recomendable enseñarle diversas técnicas para que el adolescente elija la que prefiera, desarrollarlas en varias sesiones y promover la práctica en casa (Cano-Vindel et al., 2013; Manju y Rajesh, 2015). 


\section{Reestructuración cognitiva}

En la cual se le explica la conexión entre los pensamientos emociones y conductas; además, se le instruye para que pueda identificar sus autoverbalizaciones ansiosas, creencias irracionales o esquemas disfuncionales y se plantean otras alternativas más funcionales. También se fomentan las habilidades de razonamiento, generalización, reinterpretación y modificación de pensamientos o autoinstrucciones (Cano-Vindel et al., 2013; Gomar et al., 2012).

\section{Resolución de problemas:}

Busca enseñar estrategias para hacer frente a las dificultades. En este caso, el adolescente toma un rol más activo en su proceso de afrontamiento. Para esto, se busca la identificación concreta del problema; luego, el análisis de las posibles soluciones y, por último, la aplicación de la mejor solución encontrada. Al final de la sesión, se le indica que practique en casa con situaciones evocadoras de ansiedad (Gomar et al., 2012).

\section{Exposición}

Técnica conductual de suma importancia en el tratamiento de los casos de ansiedad. A través de ella se busca que el adolescente se encuentre con el estímulo aversivo, soporte la activación emocional, aplique las habilidades de afrontamiento y genere una auténtica confianza en sí mismo; asimismo, se promueve que participe en la elaboración de una jerarquía de situaciones evocadoras de ansiedad. De esta forma, puede elegir, en colaboración con el terapeuta, las situaciones a las que será expuesto; es así que puede distinguir los peligros reales de los imaginarios de forma directa, sintiendo un mayor control sobre sus emociones (Friedberg y McClure, 2005; Gomar et al., 2012). Dichos ejercicios se enseñan en consulta y se practican fuera de la terapia, pero luego de haber logrado cierto control emocional a través de las técnicas cognitivas (Cano-Vindel et al., 2013).

\section{Prevención de recaídas}

Busca fomentar la exposición como un estilo de vida, recalcando que, al término de las sesiones, no se puede retomar las rutinas de evitación anteriores, ya que generarían el retorno de los síntomas ansiosos. En ocasiones, se involucra a la familia para que participe en las tareas de exposición del adolescente. Además, se le adelanta a posibles retrocesos y se le alienta a utilizar las habilidades que adquirió en el curso de la terapia, siendo posible retornar por una sesión de refuerzo (Gomar et al., 2012). 
A su vez, se implementaron las siguientes herramientas de autoevaluación:

\section{Unidades subjetivas de malestar (SUD)}

Esta herramienta favorece que el paciente pueda medir el nivel de malestar que siente en el momento. Es una escala del 0 (nada de malestar) al 10 (nivel máximo de tensión) que se utilizó como apoyo en los ejercicios de respiración y relajación, para que el paciente pueda identificar los efectos de dichos ejercicios, de esta forma, obteniendo un feedback de los cambios de sus estados ansiosos. Realizar los ejercicios de respiración y relajación permiten que el paciente reduzca sus síntomas fisiológicos de la ansiedad, analizar sobre su nivel de malestar le permite percatarse de dichos cambios. Asimismo, se le solicitó que los utilizara para realizar sus autorregistros (Cayoun, 2014; León, 2017).

\section{Autorregistro (ver Apéndice 7)}

Utilizado para identificar en el día a día los patrones de pensamientos disfuncionales, de esta forma el paciente puede comprender mejor el círculo vicioso que abarca a los pensamientos, las emociones y las conductas (Manju y Rajesh, 2015).

\subsubsection{Procedimiento de implementación}

El programa completo se divide en tres módulos, los cuales se basan en las competencias generales (ver Figura 4.1). Consta de un total de 14 sesiones, cada una de ellas tiene un resultado de aprendizaje que se busca lograr al final. La duración de cada sesión es de 45 minutos y se realizan 2 veces a la semana, en el consultorio psicológico del centro terapéutico. 
Figura 4.1

\section{Estructura de la intervención}

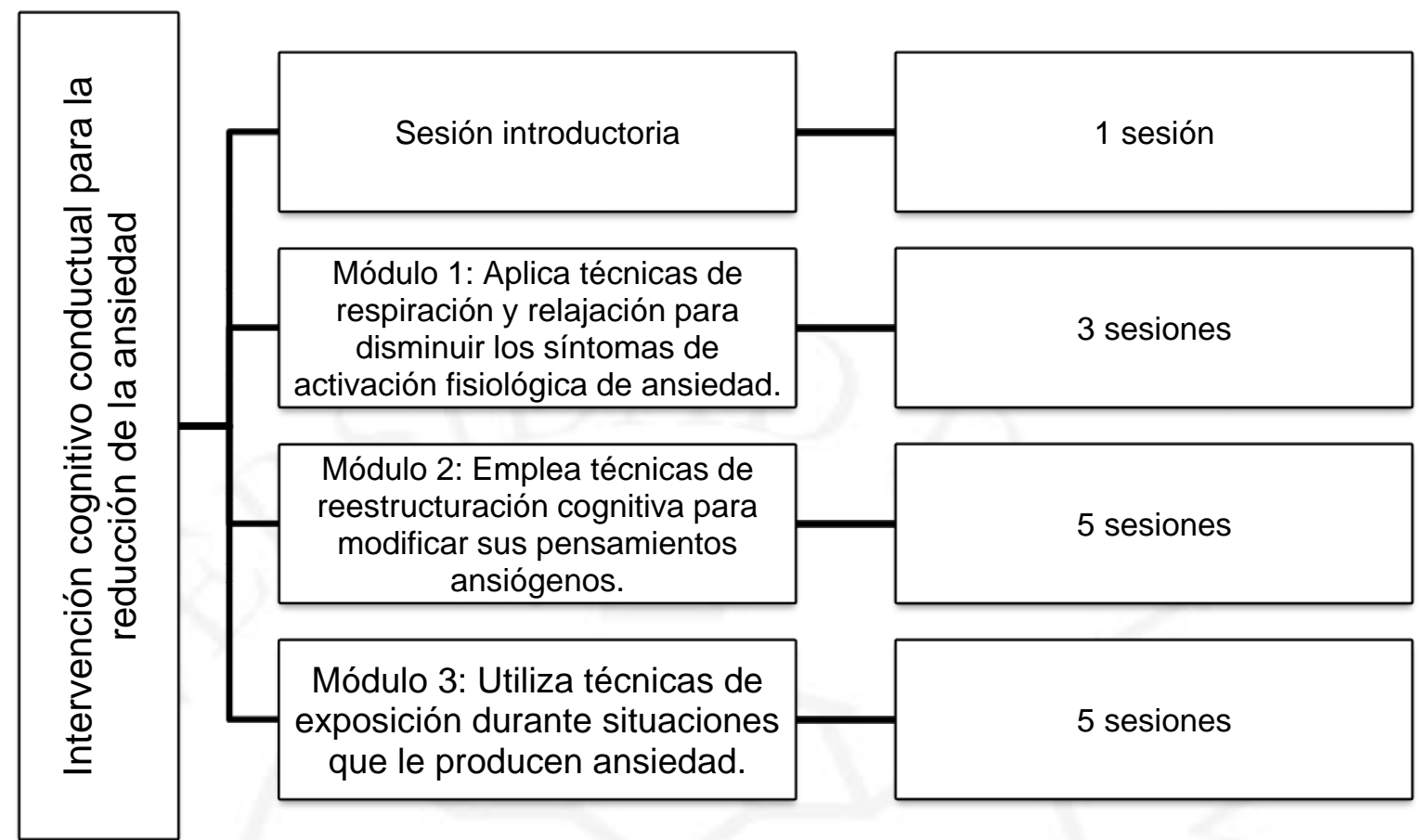

Nota: Los módulos se encuentran divididos por competencias generales.

El programa empieza con una primera sesión introductoria, que consiste en una presentación de la terapia, en la que se establecen las normas que se seguirán en la misma, se habla del tema de la confidencialidad, se explica la labor de un psicólogo y se busca aclarar dudas que puedan surgir del proceso. A su vez, se presenta el cuaderno de terapia, en el cual se llevarán a cabo los ejercicios que se harán en sesión. Dicho cuaderno permanecerá en el consultorio. Posteriormente, se establecen los objetivos con el paciente, siempre buscando brindar apertura para el diálogo y llegar a acuerdos. Por último, se comenta la frecuencia y duración de la terapia. Esta primera sesión tiene como objetivo establecer una alianza terapéutica, esto con el fin de involucrar a los pacientes en su proceso, para lograr que se sientan más confiados y así poder comentar sus problemas, participar activamente sin sentirse juzgados; además, permite que se aclaren las expectativas y, al sentirse más partícipe de su proceso, sea más probable que cumpla con las tareas que se le asignen fuera de la terapia (García y Sanz, 2016; Gomar et al., 2012).

El primer módulo se enfoca en que el paciente logre aplicar técnicas de respiración y relajación para disminuir los síntomas de activación fisiológica de la 
ansiedad. Dicho módulo consta de tres sesiones, en las cuales primero se busca psicoeducar al paciente sobre la ansiedad, la forma en que esta se manifiesta en el cuerpo, y las cogniciones y conductas que derivan de esta, esto acompañado de una ficha llamada “Ansiedad: amiga o enemiga" (ver Apéndice 6). Además, facilita la normalización de la ansiedad. En la segunda y tercera sesión se enseñan las técnicas de respiración profunda y relajación por tensión, así como el uso de la imaginería, utilizando la escala de malestar subjetivo al principio y al final de cada sesión, con el objetivo de ver el impacto de la técnica en su nivel de tensión. Las sesiones se acompañan de tareas que el paciente debe completar fuera de la sesión, con el fin de llevar los aprendizajes a otros ambientes. Algunas de las tareas involucran el llenado de autorregistros (ver Apéndice 7) o de fichas de relajación (ver Apéndice 8), en las cuales registra su nivel de malestar subjetivo (SUD) antes y después de realizar la técnica en casa.

El segundo módulo busca que el participante emplee técnicas de reestructuración cognitiva para modificar sus pensamientos ansiógenos. Dicho apartado consta de cinco sesiones. Al principio, se le presenta el modelo $\mathrm{ABC}$, en el cual se explica cómo los pensamientos influyen en nuestras emociones y conductas. Luego, se le muestran ejemplos de situaciones en las que se demuestra esto. A su vez, se busca que aprenda a identificar sus pensamientos ansiógenos y busque otros más funcionales; además de debatirlos con el fin de modificarlos. Por otro lado, se le enseña la técnica de resolución de problemas, que consta de la identificación de tres posibles soluciones ante una situación complicada, con el fin de analizar cada una y responder con la alternativa más apropiada. Lo anterior tiene como fin que el paciente tenga una perspectiva más amplia de los problemas y que pueda responder de forma más funcional. Cabe señalar que cada sesión tiene como tarea el llenado de autorregistros acerca de lo trabajado en sesión.

En cuando al tercer módulo, se enfoca en que el paciente utilice técnicas de exposición durante situaciones que le producen ansiedad. Para lograrlo, se empieza psiceoducandolo sobre la forma de mantenimiento de la ansiedad, a través de la evitación. Asimismo, se le comenta los beneficios de la exposición y se le adelanta que, durante estas tareas, probablemente sienta niveles altos de ansiedad, pero que estos disminuirán con el tiempo. Posteriormente, se realiza una jerarquía de situaciones que causan más o menos ansiedad y se escoge conjuntamente las tareas a realizar. Luego, se ejecutan desde la que causa menos ansiedad hasta la que provoca más, ya sea de forma imaginaria o en vivo, registrando el SUD al principio y al final. Cabe mencionar que se fomenta el 
reforzamiento a cada uno de sus avances. Por último, se promueve el desarrollo de las tareas fuera de la sesión, así como el llenado de los autorregistros.

La última sesión aborda la prevención de recaídas, en la cual se busca concientizar al paciente sobre la importancia de continuar con la exposición en su vida diaria; además, se refuerzan los aprendizajes en la terapia para poder afrontar los problemas venideros. Asimismo, se diferencia entre retroceso y recaída, siendo el primero un pequeño paso hacia atrás y, el segundo, un regreso a las antiguas costumbres de evitación, lo que puede suceder cuando la persona deja de practicar fuera de terapia. Ninguno de los dos significa una pérdida absoluta, las nuevas habilidades adquiridas por el paciente se encuentran disponibles para que pueda aplicarlas (Gomar et al., 2012).

\subsection{Evaluación de proceso}

\subsubsection{Participantes}

Los participantes de la evaluación de proceso fueron los mismos que se presentaron en la evaluación de línea base. Todos los participantes asistieron a las sesiones individuales.

\subsubsection{Técnicas y/o instrumentos de evaluación/diagnóstico}

Se utilizó la versión adaptada al español del Inventario de ansiedad de Beck (BAI), desarrollado por Beck, Epstein, Brown y Steer (1988).

\subsubsection{Procedimiento de evaluación de proceso}

Al término de la sesión número tres, se le entregó al paciente el Inventario de Ansiedad de Beck (BAI) y se le orientó sobre la correcta forma de llenado del mismo. A su vez, se le explicó que el propósito de la evaluación es de medir los procesos que se van dando en la terapia. Al término, se recogió la prueba. Cabe resaltar que los permisos se solicitaron para ambas evaluaciones, por lo que no se volvió a entregar un consentimiento informado para este apartado.

El análisis de los datos se realizó sumando los puntajes de cada participante y ubicándolos en una categoría. Luego, se calculó la media de los puntajes para poder comparar la diferencia entre los niveles encontrados antes y después de la intervención. A su vez, se calculó la $t$ de student para comparar las diferencias. Dichos estadísticos se 
realizaron utilizando el programa SPSS Statistics, para lo cual primero se ingresaron las variables y las puntuaciones para luego hallar las medias y la $t$ de student. 


\section{CAPÍTULO V: RESULTADOS}

\subsection{Resultados descriptivos cuantitativos}

Luego de un análisis de las puntuaciones obtenidas antes y después de las tres sesiones de intervención, se obtiene que no se presentaron cambios en cuanto a las categorías de los niveles de ansiedad antes y después de la implementación. Las medias en ambos casos se encontraban en un nivel moderado (ver Tabla 5.1).

Tabla 5.1

Nivel de ansiedad en la evaluación de línea base y de proceso

\begin{tabular}{lcccc}
\hline Evaluación & Mínimo & Máximo & Media & Categoría \\
\hline Línea base & 17 & 28 & 22 & Moderado \\
Proceso & 16 & 26 & 20 & Moderado \\
\hline
\end{tabular}

Asimismo, se realizó un análisis de las puntuaciones pre y post - test utilizando la $t$ de student para muestras relacionadas (ver Tabla 5.2). De esta forma se obtuvo que el nivel de significancia (.001) es menor a .05 , lo que significa que existen diferencias estadísticamente significativas en los niveles de ansiedad antes y después de la intervención (Hernández, Fernández y Baptista, 2014). Sin embargo, de acuerdo a Sanz (2014), para considerar que existe un cambio después de la implementación, se debe obtener una diferencia de 10 puntos en la evaluación pre y post - test del Inventario de Ansiedad de Beck. La media de las diferencias entre las puntuaciones antes y después de la intervención fue de 1.8 , lo que sugiere que no se debe considerar como progresos debido a la intervención, sobre todo al ejecutarse solo las 3 primeras sesiones. 
Tabla 5.2

t de student para la evaluación de línea base y de proceso

\begin{tabular}{lcccc}
\hline & $\begin{array}{c}\text { Diferencia de } \\
\text { Medias }\end{array}$ & $\begin{array}{c}\text { Desviación } \\
\text { estándar }\end{array}$ & $t$ & Significancia \\
\hline $\begin{array}{l}\text { Niveles de ansiedad } \\
\text { Pre y Post -test }\end{array}$ & 1.8 & .45 & 9 & .001 \\
$* p<.05$ & & &
\end{tabular}

\subsection{Resultados interpretativos}

El reporte de SUDS realizado antes y después de la sesión de respiración y relajación mostró niveles más bajos de tensión después del uso de la técnica. Esto permite que los participantes identifiquen el nivel de ansiedad que presentan y observen los cambios que se dan luego de la técnica, favoreciendo la motivación por su proceso y por seguir practicando fuera de la terapia (Cano-Vindel et al., 2013; Manju y Rajesh, 2015). Con la práctica constante de las técnicas de respiración y relajación y el uso continuo de las mismas podría lograrse la competencia general esperada al término del módulo, que sería utilizar dichas técnicas en situaciones que le generen ansiedad, con el fin de reducir los síntomas fisiológicos (Cano-Vindel et al., 2013; Manju y Rajesh, 2015).

Tabla 5.3

Comparación entre los SUD inicial y final aplicados en la tercera sesión

\begin{tabular}{ccc}
\hline Paciente & SUD Inicial & SUD Final \\
\hline 1 & $8 / 10$ & $3 / 10$ \\
2 & $7 / 10$ & $3 / 10$ \\
3 & $6 / 10$ & $3 / 10$ \\
4 & $5 / 10$ & $2 / 10$ \\
5 & $8 / 10$ & $2 / 10$ \\
\hline
\end{tabular}

Por otro lado, aún no se puede observar el impacto institucional que deriva de la implementación del programa ya que solo se aplicaron 3 sesiones. Sin embargo, la elaboración del programa permite tener una base para poder tratar los problemas de 
ansiedad en futuros pacientes, así como fichas y materiales que se pueden utilizar más adelante. Además, permite tomar en cuenta la necesidad de realizar evaluaciones de proceso cada cierto tiempo, para poder corroborar la eficacia de las intervenciones que se realicen y de esta forma replicarlas con sus respectivas modificaciones en cada caso. Asimismo, le permite concientizarse sobre la importancia de un buen manejo de la base de datos de los pacientes, para poder plantear programas que busquen tratar los problemas más comunes.

Entre las limitaciones prácticas observadas se encuentra que algunos pacientes no desean realizar los autorregistros que se les asignan para la casa, lo que puede dificultar el cumplimiento del objetivo de la sesión. En cuanto a las limitaciones metodológicas, se asignó un número de sesiones para todo el programa; sin embargo, cada paciente es diferente, por lo que podrían necesitarse más sesiones si el caso lo requiere. 


\section{CONCLUSIONES}

- En base a los resultados obtenidos en la evaluación de línea base y en la de proceso, se encontró que la media de los niveles de ansiedad en ambas situaciones era moderada. Se encontraron diferencias estadísticamente significativas entre ambas evaluaciones; sin embargo, no se podría considerar como mejoras debido a la intervención, ya que solo se ejecutaron tres sesiones del programa. Se realizó solo una sesión de técnicas de respiración y relajación, lo que significa que los participantes recién están aprendiendo a realizarlas y aún no se cumple con el objetivo del primer módulo, que consiste en reducir los síntomas fisiológicos de la ansiedad a través de la psicoeducación y el empleo de técnicas de respiración y relajación. 


\section{RECOMENDACIONES}

- Finalizar el programa de intervención completo y realizar una evaluación al final para comprobar si efectivamente hubo una reducción de los niveles de ansiedad en los participantes. 


\section{REFERENCIAS}

Aparicio M. y Zermeño C. (2010). Relaciones familiares y nuevas tecnología en el siglo XXI. Recuperado de http://www.unav.es/icf/main/top/2010/AparicioZermeno_Relaciones-familiares-nuevas-tecnologias.pdf

Barlow, D. (2018). Manual clínico de trastornos psicológicos: Tratamiento paso a paso. Recuperado de https://ebookcentral.proquest.com

Beck, A. y Clark, D. (2012). Terapia cognitiva para trastornos de ansiedad. España: Desclée de Brouwer.

Beck, A., Emery, G. \& Greenberg, R. (2005). Anxiety disorders and phobias: A cognitive perspective. Estados Unidos: Basic Books.

Beck, A., Epstein, N., Brown, G. \& Steer, R. (1988). An inventory for measuring clinical anxiety: Psychometric properties. Journal of Consulting and Clinical Psychology, 56, 893-897. https://doi.org/10.1.1.471.4319

Beck, A. y Steer, R. (2011). Manual. BAI. Inventario de Ansiedad de Beck (Adaptación española de Sanz, J.). Madrid: Pearson Educación.

Bunge, E., Gomar, M. y Mandil, J. (2009). Terapia cognitiva con niños y adolescentes: Aportes técnicos (2. ${ }^{a}$ ed.). Buenos Aires: Librería Akadia Editorial.

Calla, N. e Infantes, K. (2020). Autoestima y ansiedad en escolares de educación secundaria en instituciones estatales y particulares (tesis de grado). Universidad Católica de Santa María. Recuperado de http://tesis.ucsm.edu.pe/repositorio/bitstream/handle/UCSM/9833/76.0409.PS.p df? sequence $=1 \&$ is Allowed $=y$

Cano-Vincel, A., Dongil-Collado, E., Salguero, J. y Wood, C. (2013). Intervención cognitivo-conductual en los trastornos de ansiedad: una actualización. Información Psicològica, 102, 4-27. Recuperado de https://www.researchgate.net/publication/230577051_Intervencion_cognitivoconductual_en_los_trastornos_de_ansiedad_una_actualizacion_Cognitivebehavioral_intervention_for_anxiety_disorders_An_update

Capo, M. (2011). Mis hijos y las drogas: Prevención a través del clima familiar afectivo. Colombia: Ediciones de la U.

Cárdenas, E. M., Feria, M., Palacios, L. y de la Peña, F. (2010). Guía clínica para los trastornos de ansiedad en niños y adolescentes. México: Instituto Nacional de Psiquiatría Ramón de la Fuente y Secretaría de Salud. Recuperado de http://inprfcd.gob.mx/guiasclinicas/trastornos_de_ansiedad.pdf 
Cayoun, B. (2014). TCC con Mindfulness Integrado: Principios y Práctica. España: Descleé de Brouwer. Recuperado de https://ebookcentral-proquestcom.ezproxy.ulima.edu.pe

Cevallos, Y. y Proaño, A. (2016). Habilidades sociales y ansiedad en estudiantes de octavo, noveno y décimo grado de la Unidad Educativa Dr. Ricardo Cornejo Rosales (tesis de maestría). Quito: UCE.

Diz, J. (2013). Desarrollo del adolescente: aspectos físicos, psicológicos y sociales. Pediatría Integral, 17(2), 88-93. Recuperado de http://biblioteca.esucomex.cl/RCA/Desarrollo\%20del\%20adolescente_aspectos $\% 20 \mathrm{f} \% \mathrm{C} 3 \%$ ADsicos, $\% 20$ psicol\%C3\%B3gicos\%20y\%20sociales.pdf

Díaz, I. (2019). Ansiedad: Revisión y Delimitación Conceptual. Summa Psicológica UST, 16(1), $42 . \quad$ Recuperado de http://search.ebscohost.com/login.aspx?direct=true \&db=edb\&AN=137636969\& lang $=$ es \&site $=$ eds-live $\&$ scope $=$ site

Fernández, B. (2018). Estudio de caso clínico: terapia cognitiva en un trastorno de pánico (tesis de grado). Lima: Universidad San Martin de Porres. Recuperado de http://repositorio.usmp.edu.pe/handle/usmp/3529

Friedberg, R. y McClure, J. (2005). Práctica clínica de terapia cognitiva con niños y adolescentes. Barcelona: Paidós.

Gallagher, M., Phillips, C., D'Souza, J., Richardson, A., Long, L., Boswell, J., Farchione, T. \& Barlow, D. (2020). Trajectories of change in well-being during cognitive behavioral therapies for anxiety disorders: Quantifying the impact and covariation with improvements in anxiety. Psychotherapy 57(1). https://doi.org/10.1037/pst0000283

García, M. y Sanz, J. (2016). Tratamientos de los trastornos depresivos y de ansiedad en niños y adolescentes. De la investigación a la consulta. Madrid: Ediciones Pirámide.

González, C., Guevara, Y., Jiménez, D. y Alcázar, R. (2018). Relación entre asertividad, rendimiento académico y ansiedad en una muestra de estudiantes mexicanos de secundaria. Acta Colombiana de Psicología, 21(1), p. 116-127.

Gomar, M; Mandil, J. y Bunge, E. (2012). Manual de terapia cognitivo comportamental para niños y adolescentes (1. ${ }^{\mathrm{a}}$ ed.). Argentina: Polemos.

Hartmann, P. (2019). Anxiety. Magill's Medical Guide (Online Edition). Recuperado de http://search.ebscohost.com/login. aspx?direct=true $\& d b=e r s \& A N=89093346 \&$ la ng $=$ es\& site $=$ eds-live $\&$ scope $=$ site

Hernández, S., Fernández, C. y Baptista, L. (2014). Metodología de la investigación (6º ed.). México: McGraw Hill. 
Hospital Víctor Larco Herrera (2019). Actividades de Salud del Hospital Víctor Larco Herrera.: Mes de Octubre 2019. Recuperado de https://mail.larcoherrera.gob.pe/images/documentos/estadisticas/epidemiologia/ 2019/BOLETIN_EPI_OCTUBRE_2019.pdf

Huertas, L. (2018). Estudio de caso clínico: Intervención cognitivo conductual en un caso clínico de fobia social (tesis de grado). Universidad San Martin de Porres. Recuperado de http://repositorio.usmp.edu.pe/handle/usmp/4532

Instituto Nacional de Estadística e Informática. (2016). Perú: Natalidad, Mortalidad y Nupcialidad, 2016. Recuperado de https://www.inei.gob.pe/media/MenuRecursivo/publicaciones_digitales/Est/Lib 1485/libro.pdf

Instituto Nacional de Salud Mental "Honorio Delgado Hideyo Noguchi”. (2007). Estudio Epidemiológico de Salud Mental en Niños y Adolescentes en Lima Metropolitana y Callao 2007. Informe General. Anales de Salud Mental. Recuperado de http://www.insm.gob.pe/investigacion/archivos/estudios/2007-ASM-EESMNYA.pdf

Instituto Nacional de Salud Mental "Honorio Delgado Hideyo Noguchi”. (2012). Informe Estadístico del Tercer Bimestre: Indicadores hospitalarios. Recuperado de http://www.insm.gob.pe/oficinas/estadistica/archivos/informesestadisticos/IE2012-III.pdf

León, M. (2017). Tratamiento conductual-cognitivo de la ansiedad social: Un estudio de caso. Acta Psicológica Peruana, 2(2), 301 - 318. Recuperado de http://revistas.autonoma.edu.pe/index.php/ACPP/article/view/81/63

López, F. (2014). Adolescencia: límites imprecisos. España: Larousse Alianza Editorial.

Magán, I., Sanz, J. \& García-Vera, M. (2008). Psychometric properties of a Spanish version of the Beck Anxiety Inventory (BAI) in general population. The Spanish Journal of Psychology, 11, 626-640. Recuperado de https://www.ncbi.nlm.nih.gov/pubmed/18988448

Martin-Romo, J. (2012). Actualización en modelos y técnicas de intervención psicoterapéutica $\quad\left(2 .^{\mathrm{a}}\right.$ ed.). https://ebookcentral.proquest.com/lib/bibudlimasp/reader.action?docID=580964 $8 \&$ query=terapia+cognitivo+conductual+

Manju, R. \& Rajesh, S. (2015). A Practical Approach to Cognitive Behaviour Therapy for Adolescents. Nueva Delhi: Springer.

Ministerio de Salud del Perú. (2018). Lineamientos de política sectorial en salud mental Perú 2018. Recuperado de http://bvs.minsa.gob.pe/local/MINSA/4629.pdf

Miranda, L. (2018). Estudio de caso clínico: Programa de intervención cognitivoconductual para un caso de trastorno de panic (tesis de grado). Universidad San Martin de Porres. Recuperado de http://repositorio.usmp.edu.pe/handle/usmp/3940 
Moreno (2013). Niños, adolescentes y adicciones: Una mirada desde la prevención. México: Editorial Trillas.

Moreno, V. (2016). Evidencia de la eficacia de la terapia cognitivo conductual, mediante neuro-imagen, en trastornos de ansiedad (tesis de grado). España: Universidad Autónoma de Barcelona. Recuperado de https://ddd.uab.cat/pub/tfg/2016/169278/Informe_Victor_Moreno_1196727_DD D.pdf

Núñez, I. y Crismán, R. (2016). La ansiedad como variable predictora de la autoestima en adolescentes y su influencia en el proceso educativo y en la comunicación. Revista Iberoamericana de Educación, 71(1), 109-127. https://doi.org/10.35362/rie71219

Organización Mundial de la Salud. (2018). Adolescentes: riesgos para la salud y soluciones. Recuperado de https://www.who.int/es/news-room/factsheets/detail/adolescents-health-risks-and-solutions

Organización Panamericana de la Salud. (2018). La carga de los trastornos mentales en la Región de las Américas, 2018. Recuperado de http://iris.paho.org/xmlui/handle/123456789/49578

Rasing, S., Creemers, D., Janssens, J. y Scholte, R. (2013). Effectiveness of depression and anxiety prevention in adolescents with high familial risk: study protocol for a randomized controlled trial. BMC psychiatry, 13(1), 316. https://doi.org/10.1186/1471-244X-13-316

Reyes, M. (2019). Trastornos de ansiedad. Medicine: Programa de Formación Médica Continuada Acreditado, 12(84), 4911-4917. https://doi.org/10.1016/j.med.2019.07.001

Ruiz, F., Díaz, G. y Villalobos, C. (2012). Manual de técnicas de intervención cognitiva conductuales. https://ebookcentral.proquest.com/lib/bibudlimasp/reader.action?docID=320653 $8 \&$ query=terapia+cognitivo+conductual+

Simon, D. (2016). School-Centered Interventions: Evidence-Based Strategies for Social, Emotional, and Academic Success. Washington DC: American Psychological Association.

Sánchez, J. Ontiveros, D. y Granados, E. (2019). Rendimiento escolar y ansiedad en estudiantes mexicanos de educación secundaria. Integración Académica en Psicología., 7(21), 63-70. Recuperado de http://integracion-academica.org/31volumen-7-numero-21-2019/251-rendimiento-escolar-y-ansiedad-enestudiantes-mexicanos-de-educacion-secundaria

Santos, C. y Vallín, L. (2018). La ansiedad en la adolescencia. RqR Enfermería Comunitaria, 6(1), 21-31. Recuperado de https://www.seapaonline.org/revistas/55-rqr-enfermeria-comunitaria-vol-6-n-1invierno-2018 
Sanz, J. (2014). Recomendaciones para la utilización de la adaptación española del Inventario de Ansiedad de Beck (BAI) en la práctica clínica. Clínica y Salud, 25, 39-48. Recuperado de http://scielo.isciii.es/pdf/clinsa/v25n1/original4.pdf

Sanz, J. y Navarro, M. (2003). Propiedades psicométricas de una versión española del Inventario de Ansiedad de Beck (BAI) en estudiantes universitarios. Ansiedad y Estrés, 9(1), 59-84. Recuperado de https://www.researchgate.net/publication/285908290_Propiedades_psicometrica s_de_una_version_espanola_del_Inventario_de_Ansiedad_de_Beck_BAI_en_es tudiantes_universitarios

Sanz, J., García-Vera, M. y Fortún, M. (2012). El "Inventario de ansiedad de Beck" (BAI): propiedades psicométricas de la versión española en pacientes con trastornos psicológicos. Behavioral Psychology-Psicología Conductual, 20(3), 563-583. Recuperado de https://pesquisa.bvsalud.org/portal/resource/pt/ibc113382

Stallard, P. (2007). Pensar bien - sentirse bien: Manual práctico de terapia cognitivo conductual para niños y adolescentes. España: Desclée De Brouwer

Ticona, P. (2014). El derecho a la salud mental en el Perú en el Siglo XXI ¿Un derecho protegido o un derecho postergado por el Estado Peruano? [tesis de Grado]. Pontificia Universidad Católica del Perú. Recuperado de http://tesis.pucp.edu.pe/repositorio/bitstream/handle/20.500.12404/5560/TICON A_CANO_PAOLA_SALUD_MENTAL.pdf?sequence=1\&isAllowed=y 
APÉNDICES 


\section{Apéndice 1: Formato de entrevista psicológica del centro terapéutico}

\section{DATOS DE FILIACIÓN}

Apellidos y Nombres:

Edad:

Sexo: Fecha y lugar de nacimiento:

Grado escolar: Institución educativa

Lugar de Procedencia: Teléfono:

Fecha de entrevista:

II. MOTIVO DE CONSULTA

\section{ANTECEDENTES Y DESCRIPCIÓN DE CONDUCTA}

\section{HISTORIA PERSONAL}

Datos relevantes de su desarrollo inicial e infancia.

Embarazo:

Parto:

Desarrollo motor: 
Lenguaje:

Escolaridad - Historia Psicopedagógica:

Relaciones Interpersonales - Sociabilidad (casa, fuera de casa, centro educativo)

Funciones biológicas (sueño, apetito)

Hábitos e intereses

Enfermedades y/o accidentes

Antecedentes psicopatológicos (depresión, ansiedad, psicosis u otros).

V. HISTORIA FAMILIAR (Estructura y dinámica). Descripción del vínculo

Estructura familiar:

Padre:

Madre:

Hermanos:

Otros:

\section{OBSERVACIÓN DE CONDUCTA}


VII. ENTREVISTA CON EL NIÑO E INFORMACIÓN EXTRA 


\section{Apéndice 2: Ficha técnica del inventario de ansiedad de Beck}

(bai)

\begin{tabular}{|c|c|}
\hline Nombre del test: & Inventario de Ansiedad de Beck (BAI) \\
\hline Nombre original del test: & Beck's Anxiety Inventory \\
\hline Autor: & Beck y Steer (2011) \\
\hline Procedencia: & Estados Unidos \\
\hline Adaptación: & Sanz (2011) \\
\hline Modo de aplicación: & Individual \\
\hline Ámbito de aplicación: & Clínica \\
\hline Edades de aplicación: & Adolescentes y adultos desde los 13 años de edad \\
\hline Duración: & $5-10$ minutos \\
\hline Finalidad: & $\begin{array}{l}\text { Medir la sintomatología de la ansiedad y evaluar } \\
\text { síntomas cognitivos, emocionales, motores y } \\
\text { fisiológicos }\end{array}$ \\
\hline Composición/estructura & $\begin{array}{l}\text { La prueba mide una dimensión general de ansiedad } \\
\text { compuesta por dos factores relacionados, los cuales } \\
\text { abordan los síntomas somáticos y afectivo-cognitivos }\end{array}$ \\
\hline Baremación: & $\begin{array}{l}\text { La interpretación de las puntuaciones se basa en los } \\
\text { puntos de corte, lo cual las divide en } 4 \text { clasificaciones. } \\
\text { En el caso que el paciente obtenga puntuaciones entre } 0 \\
\text { y } 7 \text {, indicaría un nivel de ansiedad mínimo; si obtiene de } \\
8 \text { a } 15 \text { puntos, sería leve; de } 16 \text { a } 25 \text { sería moderada; y } \\
\text { de } 26 \text { a } 63 \text { sería grave }\end{array}$ \\
\hline Editores: & Pearson Educación S.A. \\
\hline Datos de publicación: & España, 2011 \\
\hline
\end{tabular}




\section{Apéndice 3: Versión española del inventario de ansiedad de Beck (bai)}

A continuación, se presentan una serie de síntomas. Marque con un aspa (X) de qué forma le ha afectado cada uno de ellos durante la última semana

\begin{tabular}{|c|c|c|c|c|}
\hline & En absoluto & $\begin{array}{l}\text { Levemente, } \\
\text { no me molesta } \\
\text { mucho }\end{array}$ & $\begin{array}{c}\text { Moderadamente } \\
\text { fue muy } \\
\text { desagradable, } \\
\text { pero podía } \\
\text { soportarlo } \\
\end{array}$ & $\begin{array}{c}\text { Severamente } \\
\text { casi no podía } \\
\text { soportarlo }\end{array}$ \\
\hline $\begin{array}{l}\text { 1. Hormigueo o } \\
\text { entumecimiento }\end{array}$ & & & & \\
\hline 2. Sensación de calor & & & & \\
\hline $\begin{array}{l}\text { 3. Debilidad en las } \\
\text { piernas }\end{array}$ & & & & \\
\hline $\begin{array}{l}\text { 4. Incapacidad para } \\
\text { relajarme }\end{array}$ & & & 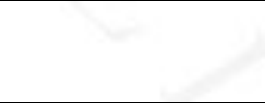 & \\
\hline $\begin{array}{l}\text { 5. Miedo a que suceda lo } \\
\text { peor }\end{array}$ & & & & \\
\hline 6. Mareos o vértigo & & & & \\
\hline $\begin{array}{l}\text { 7. Palpitaciones o } \\
\text { taquicardia }\end{array}$ & & & & \\
\hline $\begin{array}{l}\text { 8. Sensación de } \\
\text { inestabilidad }\end{array}$ & & & & 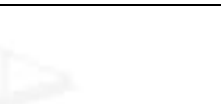 \\
\hline $\begin{array}{l}\text { 9. Sensación de estar } \\
\text { aterrorizado }\end{array}$ & & & & \\
\hline 10. Nerviosismo & & & & \\
\hline 11. Sensación de ahogo & & & & \\
\hline 12.Temblores de manos & & & & \\
\hline 13. Temblor generalizado & & & & \\
\hline $\begin{array}{l}\text { 14. Miedo a perder el } \\
\text { control }\end{array}$ & & & 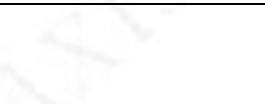 & \\
\hline $\begin{array}{l}\text { 15. Dificultad para } \\
\text { respirar }\end{array}$ & & & & \\
\hline 16. Miedo a morir & & & & \\
\hline 17. Estar asustado & & & & \\
\hline $\begin{array}{l}\text { 18. Indigestión o molestia } \\
\text { abdominal }\end{array}$ & & & & \\
\hline $\begin{array}{l}\text { 19. Sensación de } \\
\text { desmayarse }\end{array}$ & & & & \\
\hline 20. Rubor facial & & & & \\
\hline $\begin{array}{l}\text { 21. Sudoración (no debida } \\
\text { al calor) }\end{array}$ & & & & \\
\hline
\end{tabular}




\section{Apéndice 4: Consentimiento informado para investigación: Directivo de institución}

El propósito de esta ficha de consentimiento es proveer al directivo(a) de la institución educativa una clara explicación de la naturaleza de esta investigación, así como de su rol en ella como autoridad de la institución.

La presente investigación es conducida por la Bachiller de Psicología Ana Giselle Zapata Arias, de la Universidad de Lima. La meta de este estudio es estandarizar el Programa de intervención cognitivo conductual para la reducción de la ansiedad en adolescentes de un centro terapéutico privado.

Si usted accede a autorizar la realización de este estudio, se le pedirá poder aplicar tests en su institución. Esto tomará aproximadamente 5-10 minutos de su tiempo en el consultorio.

La participación en este estudio es estrictamente voluntaria. La información que se recoja será confidencial y no se usará para ningún otro propósito fuera de los de esta investigación. Las respuestas dadas en el cuestionario serán codificadas usando un número de identificación.

Si tiene alguna duda sobre este proyecto, puede hacer preguntas en cualquier momento durante la toma de pruebas y comunicarse al correo rchoy@ulima.edu.pe

Desde ya le agradecemos su participación.

Yo,

institución educativa autorizo la realización de la investigación en la del distrito de

conducida por Ana Giselle Zapata Arias. He sido informado (a) de que la meta de este estudio es estandarizar el Programa de intervención cognitivo conductual para la reducción de la ansiedad en adolescentes de un centro terapéutico privado.

Me han indicado también que se realizará la aplicación de los tests, será de 5-10 minutos en el consultorio psicológico.

Se reconoce que la participación en este estudio es estrictamente voluntaria. La información que se recoja será confidencial y no se usará para ningún otro propósito fuera de los de esta investigación. Las respuestas dadas en el cuestionario serán codificadas usando un número de identificación.

Entiendo que una copia de esta ficha de consentimiento me será entregada, y que puedo pedir información sobre los resultados de este estudio cuando éste haya concluido. Para esto, puedo contactarme al correo rchoy@ulima.edu.pe

Nombre y Firma de Directivo(a)

Fecha

de institución educativa 


\section{Apéndice 5: Consentimiento informado para evaluación psicológica: \\ Padres de los participantes}

Estimado/a padre/madre de familia,

Mi nombre es Ana Giselle Zapata Arias, Bachiller en psicología de la Universidad de Lima y me encuentro realizando la validación de un programa cognitivo conductual para la reducción de la ansiedad en adolescentes.

El presente consentimiento tiene por objetivo solicitarles su autorización para realizar una evaluación de los niveles de ansiedad de sus hijos(as) antes y después de las primeras 3 sesiones de intervención, esto con el objetivo de corroborar que los objetivos planteados para la intervención se cumplan.

La información que se obtenga de la evaluación será confidencial y no se utilizará con ningún otro propósito fuera de esta investigación. Los datos obtenidos se codificarán con un número aleatorio.

Para cualquier información adicional, puede contactarse al 20132376@ aloe.ulima.edu.pe

De antemano, agradezco su participación,

Yo, , padre, madre o apoderado del menor de años de edad, acepto de manera voluntaria que mi hijo(a) participe en el proceso de evaluación psicológica que será realizado por la bachiller Ana Giselle Zapata Arias con código 20132376 de la Facultad de Psicología de la Universidad de Lima.

Me han informado que el proceso de evaluación no perjudicará la integridad de mi hijo(a); además, conozco que se respetará la confidencialidad en todo momento y los resultados obtenidos solo se utilizarán para propósitos de la presente investigación. 


\section{Apéndice 6: Estructura completa de las sesiones de la intervención cognitivo conductual}

\begin{tabular}{|c|l|l|l|}
\hline \multicolumn{2}{|l|}{ Sesión introductoria } \\
\hline $\begin{array}{c}\text { Sesión } \\
\begin{array}{c}\mathbf{1} 45 \\
\text { minutos })\end{array}\end{array}$ & $\begin{array}{l}\text { Resultados de } \\
\text { aprendizaje } \\
\text { propósito y las } \\
\text { normas de la } \\
\text { terapia. }\end{array}$ & $\begin{array}{l}\text { Elementos } \\
\text { de objetivos } \\
\text { Contrato } \\
\text { terapéutico } \\
\text { Establecer una } \\
\text { adecuada } \\
\text { relación } \\
\text { terapéutica. }\end{array}$ & $\begin{array}{l}\text { Desarrollo } \\
\text { a su vez, se recalca que es un } \\
\text { espacio para él/ella, en donde no se } \\
\text { le va a juzgar y se va a mantener la } \\
\text { confidencialidad. } \\
\text { - Se explica lo que es un psicólogo, } \\
\text { cómo nos puede ayudar, etc. } \\
\text { - Introducimos al cuaderno de } \\
\text { terapia, en el que se realizarán los } \\
\text { ejercicios que se harán en sesión, el } \\
\text { cual se quedará en el consultorio. } \\
\text { - Se establecen objetivos con él/la } \\
\text { paciente y se escuchan las } \\
\text { expectativas sobre la terapia. } \\
\text { Además, se conversan con el fin de } \\
\text { aclarar dudas. }\end{array}$ \\
\hline
\end{tabular}


Competencia general 1: Utiliza técnicas de respiración y relajación para disminuir los síntomas de activación fisiológica de ansiedad.

\begin{tabular}{|c|c|c|c|}
\hline Sesión & $\begin{array}{l}\text { Resultados de } \\
\text { aprendizaje }\end{array}$ & Elementos & Desarrollo \\
\hline $\begin{array}{c}2 \\
(45 \\
\text { minutos })\end{array}$ & $\begin{array}{l}\text { Conoce las } \\
\text { características } \\
\text { de la ansiedad, } \\
\text { tales como las } \\
\text { respuestas } \\
\text { fisiológicas, } \\
\text { conductuales y } \\
\text { cognitivas. }\end{array}$ & $\begin{array}{l}\text { Psicoeducación } \\
\text { de la ansiedad } \\
\text { Autorregistros }\end{array}$ & $\begin{array}{l}\text { - Se explica qué es la ansiedad, } \\
\text { cómo se manifiesta en nuestro } \\
\text { cuerpo, en la forma en que vemos } \\
\text { las cosas y qué conductas surgen. } \\
\text { - Se trabaja la ficha “Ansiedad: } \\
\text { amiga o enemiga”, en la cual } \\
\text { diferenciamos entre la ansiedad que } \\
\text { surge para ayudarnos o } \\
\text { perjudicarnos. } \\
\text {-Normalización de la ansiedad } \\
\text { - Identifica los signos de ansiedad } \\
\text { en su cuerpo. } \\
\text { - Se le explica cómo llenar los } \\
\text { autorregistros, empezando con un } \\
\text { ejemplo. Se le indica que debe } \\
\text { llenarlo el resto de la semana }\end{array}$ \\
\hline $\begin{array}{l}\mathbf{3} \\
(45 \\
\text { minutos })\end{array}$ & $\begin{array}{l}\text { Conoce las } \\
\text { técnicas de } \\
\text { respiración y } \\
\text { relajación. } \\
\text { Utiliza las } \\
\text { técnicas de } \\
\text { respiración y } \\
\text { relajación para } \\
\text { disminuir los } \\
\text { síntomas }\end{array}$ & $\begin{array}{l}\text { Técnicas de } \\
\text { respiración } \\
\text { Relajación por } \\
\text { tensión }\end{array}$ & $\begin{array}{l}\text { - Revisamos los autorregistros, } \\
\text { comentando las situaciones en las } \\
\text { que se presentó la ansiedad, con qué } \\
\text { intensidad y qué síntomas físicos } \\
\text { aparecieron. } \\
\text { - Se exponen "Las enseñanzas del } \\
\text { maestro ninja", las cuales consisten } \\
\text { en aprender a relajarse para poder } \\
\text { afrontar las situaciones de forma } \\
\text { tranquila. }\end{array}$ \\
\hline
\end{tabular}




\begin{tabular}{|c|c|c|c|}
\hline & $\begin{array}{l}\text { físicos de la } \\
\text { ansiedad }\end{array}$ & & $\begin{array}{l}\text { - Se introduce la escala de malestar } \\
\text { subjetivo (SUD) en la cual debe } \\
\text { registrar el nivel de tensión del } 1 \text { al } \\
10 \text { que siente (antes de empezar las } \\
\text { técnicas y al final de la sesión) } \\
\text { - Se presenta la respiración } \\
\text { diafragmática. } \\
\text { - Luego, la relajación por tensión } \\
\text { muscular. } \\
\text { - Se fomenta la práctica de estas } \\
\text { técnicas en casa a través de } \\
\text { autorregistros, en los cuales debe } \\
\text { colocar el momento en que realizó la } \\
\text { técnica y el SUD antes y después. }\end{array}$ \\
\hline $\begin{array}{l}\mathbf{4} \\
(45 \\
\text { minutos })\end{array}$ & $\begin{array}{l}\text { Conoce las } \\
\text { técnicas de } \\
\text { respiración y } \\
\text { relajación. } \\
\text { Utiliza las } \\
\text { técnicas de } \\
\text { respiración y } \\
\text { relajación. }\end{array}$ & $\begin{array}{l}\text { Técnicas de } \\
\text { respiración } \\
\text { Relajación por } \\
\text { tensión muscular } \\
\text { Relajación } \\
\text { diferencial }\end{array}$ & $\begin{array}{l}\text { - Se revisan los autorregistros de la } \\
\text { semana anterior. } \\
\text { - Repaso de las técnicas de } \\
\text { respiración, relajación e imaginería. } \\
\text { - Se le enseña la relajación } \\
\text { diferencial. } \\
\text { - Tarea: Seguir aplicando las } \\
\text { técnicas en casa y llenar los registros } \\
\text { de relajación. }\end{array}$ \\
\hline
\end{tabular}


Competencia general 2: Emplea técnicas de reevaluación cognitiva para modificar sus pensamientos ansiógenos.

\begin{tabular}{|c|c|c|c|}
\hline $\begin{array}{l}\mathbf{5} \\
(45 \\
\text { minutos })\end{array}$ & $\begin{array}{l}\text { Reconoce el } \\
\text { efecto de sus } \\
\text { pensamientos } \\
\text { en sus } \\
\text { emociones y } \\
\text { conductas. } \\
\text { Distingue los } \\
\text { diferentes tipos } \\
\text { de distorsiones } \\
\text { cognitivas. }\end{array}$ & $\begin{array}{l}\text { Técnica de } \\
\text { relajación y } \\
\text { respiración } \\
\text { Técnica ABC } \\
\text { Reestructuración } \\
\text { cognitiva }\end{array}$ & $\begin{array}{l}\text { - Se refuerzas los aprendizajes sobre } \\
\text { las técnicas de respiración y } \\
\text { relajación por tensión muscular. } \\
\text {-Se expone el modelo ABC, en el } \\
\text { que nuestros pensamientos influyen } \\
\text { en cómo nos sentimos y actuamos. } \\
\text { - Se le explica que si cambiamos los } \\
\text { pensamientos, podemos cambiar } \\
\text { nuestras emociones y conductas. } \\
\text { - Observamos casos (historietas) de } \\
\text { diversas situaciones que provocaron } \\
\text { respuestas diferentes en cada } \\
\text { persona. } \\
\text { - Escribimos los pensamientos que } \\
\text { pudieron ocasionar tal respuesta. } \\
\text { - Se describen los pensamientos } \\
\text { automáticos o el diálogo interno } \\
\text { - Conoce algunos tipos de } \\
\text { distorsiones cognitivas } \\
\text { - Tarea para la casa: Llenar } \\
\text { autorregistros con el modelo ABC }\end{array}$ \\
\hline $\begin{array}{l}\mathbf{6} \\
(45 \\
\text { minutos })\end{array}$ & $\begin{array}{l}\text { Identifica sus } \\
\text { distorsiones } \\
\text { cognitivas }\end{array}$ & $\begin{array}{l}\text { Reestructuració } \\
\text { n cognitiva }\end{array}$ & $\begin{array}{l}\text { - Revisión de la tarea, se conversa } \\
\text { cuales fueron los pensamientos y se } \\
\text { reconoce su efecto en la ansiedad. } \\
\text { - Se le ayuda a describir una } \\
\text { situación con su respectivo } \\
\text { pensamiento, emoción, conducta y } \\
\text { respuesta fisiológica. } \\
\text { - Se repasan las distorsiones } \\
\text { cognitivas y se elige las que más }\end{array}$ \\
\hline
\end{tabular}




\begin{tabular}{|c|c|c|c|}
\hline & & & $\begin{array}{l}\text { presenta el paciente } \\
\text { - Tarea para la casa: Llenar } \\
\text { autorregistros con el modelo ABC }\end{array}$ \\
\hline $\begin{array}{l}7 \\
(45 \\
\text { minutos })\end{array}$ & $\begin{array}{l}\text { Busca } \\
\text { pensamientos } \\
\text { alternativos } \\
\text { más } \\
\text { funcionales }\end{array}$ & $\begin{array}{l}\text { Reestructuració } \\
\text { n cognitiva } \\
\text { Autoinstruccio } \\
\text { nes }\end{array}$ & $\begin{array}{l}\text { - Repaso de la sesión anterior y } \\
\text { llenado de una ficha sobre el } \\
\text { reconocimiento de los pensamientos } \\
\text { que surgen cuando estamos } \\
\text { ansiosos. } \\
\text { - Busca alternativas más racionales } \\
\text { para responder frente a las } \\
\text { situaciones. } \\
\text {-Se fomentan } \\
\text { autoverbalizaciones } \\
\text { afrontamiento } \\
\text { - Se presentan algunas preguntas } \\
\text { que puede utilizar para desafiar a los } \\
\text { pensamientos disfuncionales. } \\
\text { - Tarea para la casa: Llenar } \\
\text { autorregistros con el modelo ABC; } \\
\text { así como el planteamiento de una } \\
\text { nueva verbalización que sea más } \\
\text { funcional. }\end{array}$ \\
\hline $\begin{array}{l}\mathbf{8} \\
(45 \\
\text { minutos })\end{array}$ & $\begin{array}{lr}\text { Identifica } & \text { el } \\
\text { problema } & \text { y } \\
\text { realiza } & \text { una } \\
\text { lista } & \text { de } \\
\text { posibles } & \\
\text { soluciones } & \end{array}$ & $\begin{array}{l}\text { Resolución de } \\
\text { problemas }\end{array}$ & $\begin{array}{l}\text { - Revisión de las tareas de la semana } \\
\text { anterior, repasando el modelo del } \\
\text { ABC y comentando qué } \\
\text { pensamientos alternativos propuso. } \\
\text { - Se conversa sobre los problemas } \\
\text { más conflictivos en su día a día, se } \\
\text { identifican algunos que generan } \\
\text { mayores niveles de ansiedad. }\end{array}$ \\
\hline
\end{tabular}




\begin{tabular}{|l|l|l|l|}
\hline $\begin{array}{l}\text { Analiza cada } \\
\text { alternativa, } \\
\text { evaluando sus } \\
\text { pros y contras. }\end{array}$ & $\begin{array}{l}\text { - Se le presenta la ficha del } \\
\text { semáforo, que le permite saber que, } \\
\text { para resolver un problema primero } \\
\text { debemos parar, buscar } 3 \text { posibles } \\
\text { soluciones y escoger una de ellas. } \\
\text { - Practicamos con algunos ejemplos } \\
\text { de situaciones, pensando } 3 \text { posibles } \\
\text { soluciones, analizando cada una y } \\
\text { escogiendo la más conveniente. } \\
\text { - Tarea para casa: Se le indica que } \\
\text { escriba durante la semana algún } \\
\text { problema que tuvo, las soluciones } \\
\text { que planteó, lo que hizo y las } \\
\text { consecuencias. }\end{array}$ \\
\hline
\end{tabular}


Competencia general 3: Utiliza técnicas de exposición en situaciones que le producen ansiedad

\begin{tabular}{|c|c|c|c|}
\hline $\begin{array}{l}\mathbf{1 0}-\mathbf{1 3} \\
(45 \\
\text { minutos })\end{array}$ & $\begin{array}{l}\text { Reconoce las } \\
\text { señales de } \\
\text { seguridad del } \\
\text { ambiente para } \\
\text { afrontar las } \\
\text { situaciones. } \\
\text { Reconoce la } \\
\text { influencia de la } \\
\text { evitación en el } \\
\text { mantenimiento } \\
\text { de la ansiedad. } \\
\text { Se expone a } \\
\text { situaciones que } \\
\text { le provoquen } \\
\text { ansiedad. }\end{array}$ & Exposición & $\begin{array}{l}\text { - Repasamos el ejercicio de } \\
\text { resolución de problemas de la sesión } \\
\text { anterior. } \\
\text { - Psicoeducación sobre la forma de } \\
\text { mantenimiento de la ansiedad, a } \\
\text { través de la evitación. } \\
\text { - Selección conjunta de las tareas de } \\
\text { exposición que se practicarán } \\
\text { durante la sesión, se realiza una } \\
\text { jerarquía de las que causan más o } \\
\text { menos ansiedad. } \\
\text { - Preparación para la tarea. } \\
\text { - Ejecución de la tarea elegida, ya } \\
\text { sea de forma imaginaria o en vivo. } \\
\text { - Evaluación del malestar subjetivo } \\
\text { durante la tarea y después. } \\
\text { - Premio al esfuerzo } \\
\text { - Tarea para casa: llevar a cabo las } \\
\text { tareas de exposición, registrando el } \\
\text { SUD antes y después. }\end{array}$ \\
\hline $\begin{array}{l}\mathbf{1 4} \\
(45 \\
\text { minutos })\end{array}$ & $\begin{array}{l}\text { Se expone a } \\
\text { situaciones } \\
\text { que le } \\
\text { provoquen } \\
\text { ansiedad }\end{array}$ & $\begin{array}{l}\text { Prevención de } \\
\text { recaídas }\end{array}$ & $\begin{array}{l}\text { - Revisión de la tarea de } \\
\text { autorregistro. } \\
\text { - Se busca concientizar al paciente } \\
\text { sobre la importancia de continuar } \\
\text { con la exposición en su vida diaria. } \\
\text { - Se refuerzan los aprendizajes en la } \\
\text { terapia para poder afrontar los } \\
\text { problemas venideros. } \\
\text { - Se diferencia entre retroceso y } \\
\text { recaída, siendo el primero un }\end{array}$ \\
\hline
\end{tabular}




\begin{tabular}{|l|l|l|}
\hline & $\mid \begin{array}{l}\text { pequeño paso hacia atrás y, el } \\
\text { segundo, un regreso a las antiguas } \\
\text { costumbres de evitación, lo que } \\
\text { puede suceder cuando la persona } \\
\text { deja de practicar fuera de terapia. } \\
\text { - Se enfatiza en que ninguno de los } \\
\text { dos significa una pérdida absoluta, } \\
\text { las nuevas habilidades adquiridas } \\
\text { por el paciente se encuentran } \\
\text { disponibles para que pueda } \\
\text { aplicarlas }\end{array}$ \\
\hline
\end{tabular}




\section{Apéndice 7: Ficha "ansiedad: amiga o enemiga"}

\section{(Bunge, Gomar y Mandil; 2009)}

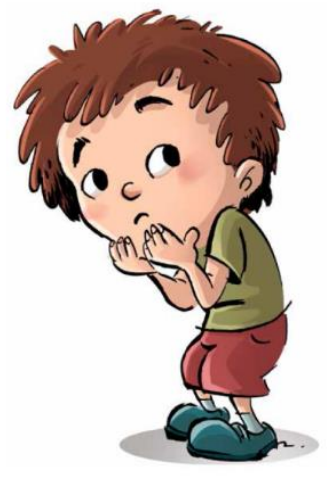

A veces, la ansiedad puede ser nuestra amiga; ya que funciona como una alarma natural que se prende ante eventos peligrosos o difíciles, alertando a nuestro cuerpo y mente para responder de forma rápida. Incluso podemos llegar a correr o decidir en menos tiempo.

A veces la ansiedad es nuestra enemiga, en los casos en que aparece intensa y frecuentemente; ya que hace que estemos siempre nerviosos ante amenazas irreales. Es como una alarma que se encuentra malograda y suena cuando no hay ningún peligro real.

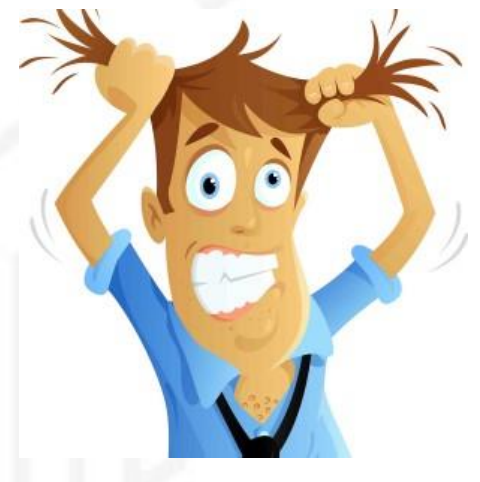

Escribe alguna situación en la que tus alarmas funcionaron bien y otra en la que funcionaron mal

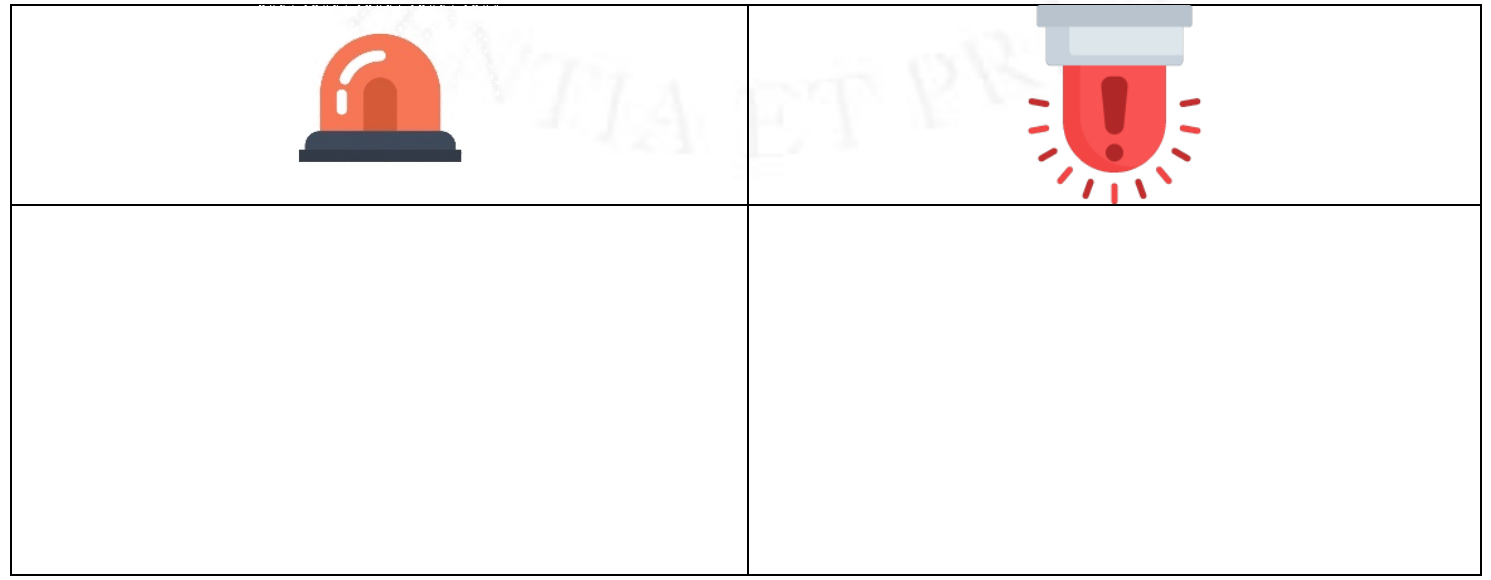


Apéndice 8: Autorregistros

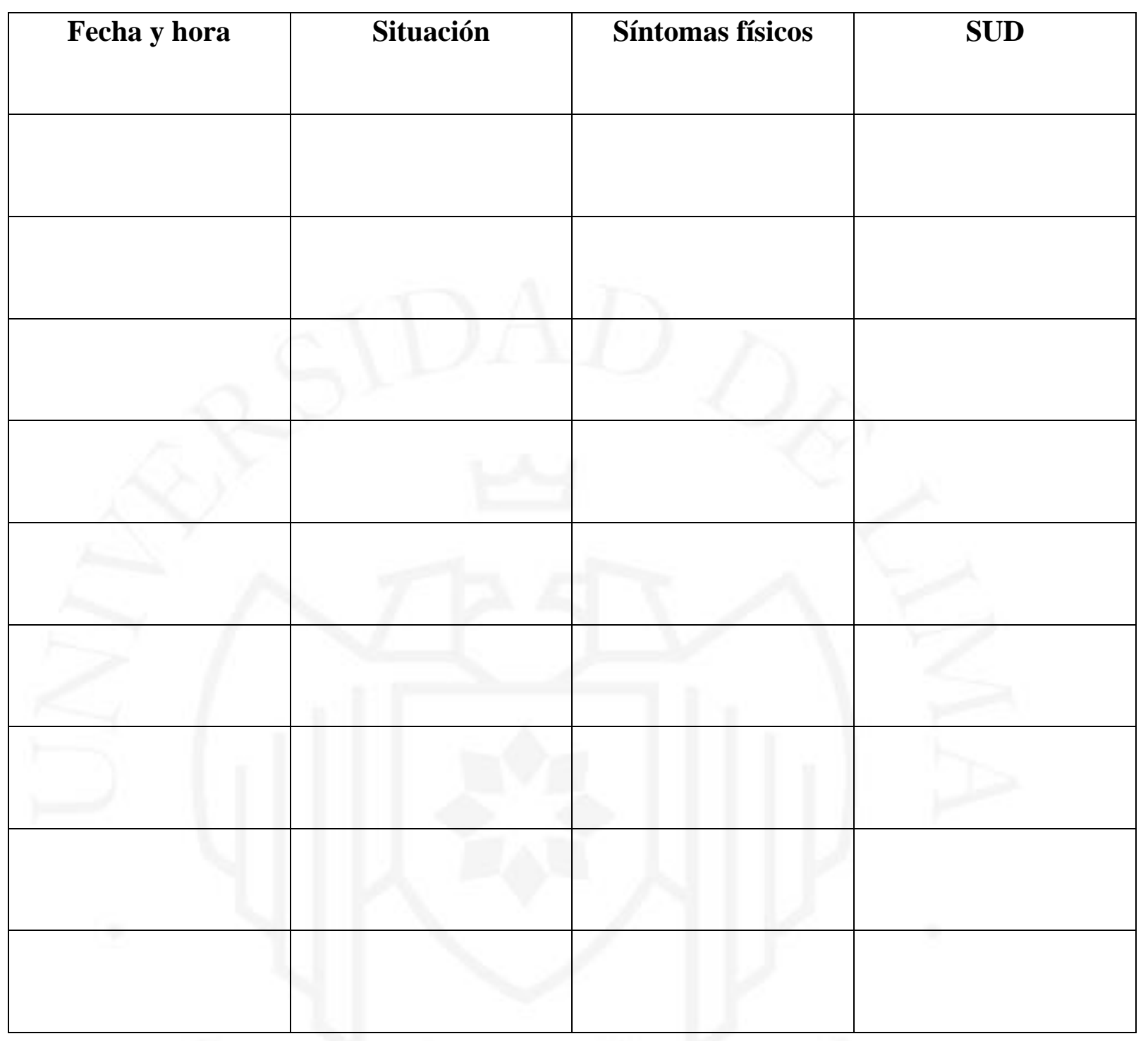


Apéndice 9: Registro de relajación

Nombre:

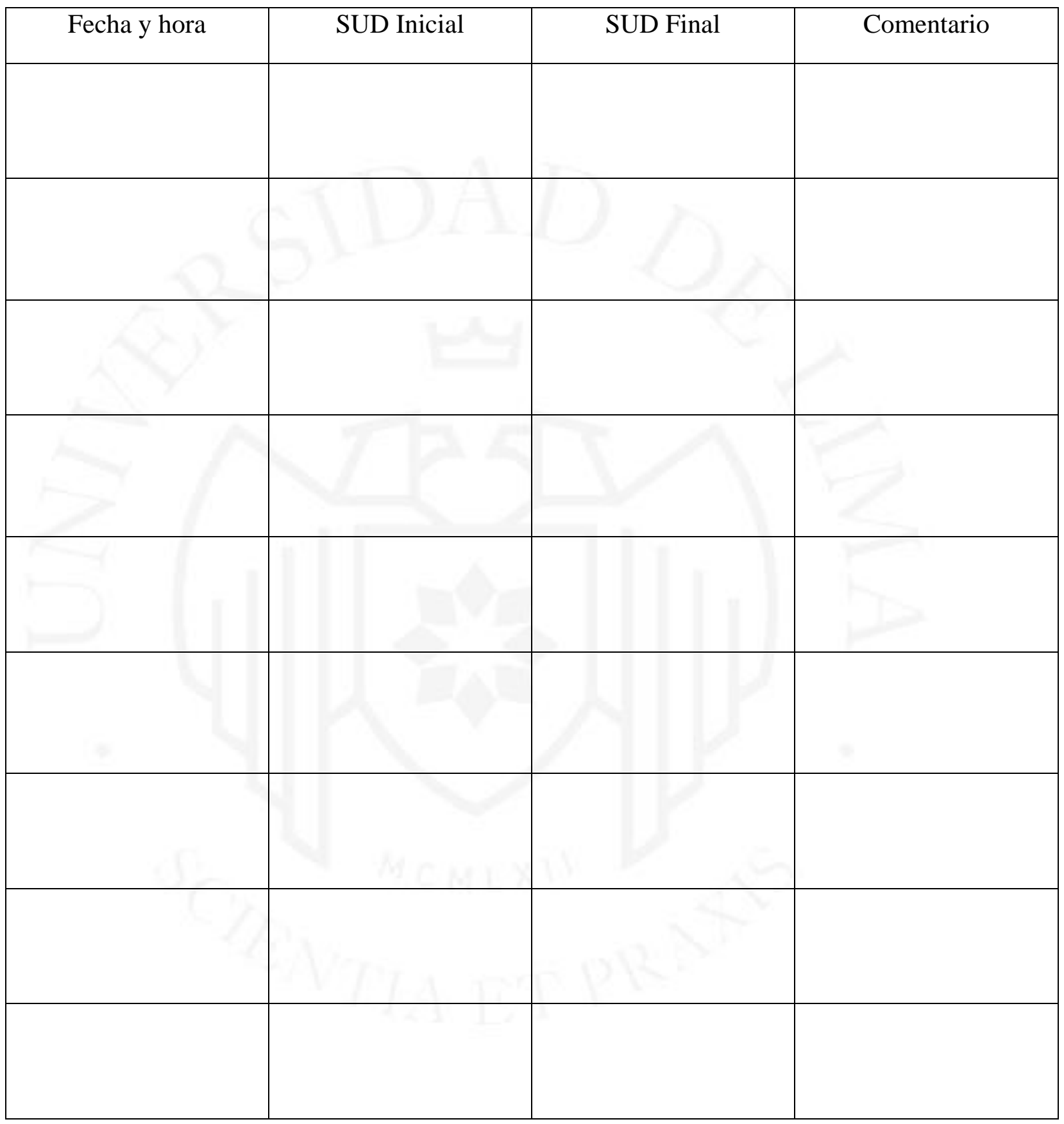




\section{Apéndice 10: Matriz organizativa adaptada}

\begin{tabular}{|c|c|c|}
\hline \multirow{2}{*}{\multicolumn{3}{|c|}{$\begin{array}{l}\text { Intervención cognitivo conductual para la reducción de la ansiedad en } \\
\text { adolescentes de un centro terapéutico privado } \\
\text { Objetivo: Reducir los niveles de ansiedad en adolescentes entre } 13 \text { y } 15 \text { años de edad } \\
\text { que asisten a un centro terapéutico privado. }\end{array}$}} \\
\hline & & \\
\hline Competencias & $\begin{array}{l}\text { Resultados de } \\
\text { aprendizaje }\end{array}$ & Indicadores \\
\hline $\begin{array}{l}\text { Aplica técnicas de } \\
\text { respiración y relajación } \\
\text { para disminuir los síntomas } \\
\text { de activación fisiológica de } \\
\text { ansiedad. }\end{array}$ & $\begin{array}{l}\text { - } \text { Conoce las } \\
\text { características de la } \\
\text { ansiedad, tales como las } \\
\text { respuestas fisiológicas, } \\
\text { conductuales } \\
\text { cognitivas. } \\
\text { - Identifica las respuestas } \\
\text { fisiológicas de la } \\
\text { ansiedad. } \\
\text { - Conoce las técnicas de } \\
\text { respiración y relajación. } \\
\text { - Utiliza las técnicas de } \\
\text { respiración y relajación. }\end{array}$ & $\begin{array}{l}\text { \# de características de } \\
\text { ansiedad identificadas } \\
\text { \# de síntomas fisiológicos } \\
\text { de ansiedad identificados } \\
\text { en su cuerpo } \\
\text { \# de ejercicios de } \\
\text { respiración realizados } \\
\text { \# de ejercicios de } \\
\text { relajación por tensión } \\
\text { muscular realizados }\end{array}$ \\
\hline $\begin{array}{l}\text { Emplea técnicas de } \\
\text { reestructuración cognitiva } \\
\text { para modificar sus } \\
\text { pensamientos ansiógenos. }\end{array}$ & $\begin{array}{l}\text { - Distingue los diferentes } \\
\text { tipos de distorsiones } \\
\text { cognitivas. } \\
\text { - Reconoce el efecto de } \\
\text { sus pensamientos en sus } \\
\text { emociones y conductas. } \\
\text { - Identifica sus } \\
\text { distorsiones cognitivas } \\
\text { - Busca pensamientos } \\
\text { alternativos más } \\
\text { funcionales }\end{array}$ & $\begin{array}{l}\text { \# de distorsiones } \\
\text { cognitivas identificadas } \\
\text { correctamente } \\
\text { \# de registros ABC } \\
\text { realizados } \\
\text { \# de pensamientos } \\
\text { disfuncionales } \\
\text { reemplazados por } \\
\text { funcionales }\end{array}$ \\
\hline
\end{tabular}




\begin{tabular}{|c|c|c|}
\hline & $\begin{array}{l}\text { - Identifica sus problemas } \\
\text { y realiza una lista de } \\
\text { posibles soluciones } \\
\text { - Analiza cada alternativa, } \\
\text { evaluando sus pros y } \\
\text { contras } \\
\text { - Escoge la mejor } \\
\text { alternativa y la ejecuta. }\end{array}$ & $\begin{array}{l}\text { \# posibles soluciones } \\
\text { planteadas frente a un } \\
\text { problema } \\
\text { \# de ejercicios de } \\
\text { resolución de problemas } \\
\text { completos ejecutados }\end{array}$ \\
\hline $\begin{array}{l}\text { Utiliza técnicas de } \\
\text { exposición durante } \\
\text { situaciones que le } \\
\text { producen ansiedad. }\end{array}$ & $\begin{array}{l}\text { - Reconoce las señales de } \\
\text { seguridad del ambiente } \\
\text { para afrontar las } \\
\text { situaciones. } \\
\text { - Reconoce la influencia } \\
\text { de la evitación en el } \\
\text { mantenimiento de la } \\
\text { ansiedad. } \\
\text { - Se expone a situaciones } \\
\text { que le provoquen } \\
\text { ansiedad. }\end{array}$ & $\begin{array}{l}\text { \# de señales de seguridad } \\
\text { identificadas } \\
\text { \# de situaciones a las que } \\
\text { se expuso }\end{array}$ \\
\hline
\end{tabular}

